UNIVERSIDADE DE SÃO PAULO

FACULDADE DE MEDICINA DE RIBEIRÃO PRETO

SIGRID LORENA BATISTA ARRUDA

Manifestações clínicas e complicações associadas à toxoplasmose ocular 


\section{Manifestações clínicas e complicações associadas à toxoplasmose ocular}

Dissertação apresentada à Faculdade de Medicina de Ribeirão Preto da Universidade de São Paulo para obtenção do Título de Mestre em Ciências.

Área de Concentração: Mecanismos Fisiopatológicos nos Sistemas Visual e ÁudioVestibular

Orientador: Prof. Dr. João Marcello Fórtes Furtado

Coorientadora: Profa. Dra. Justine Ruth Smith 
AUTORIZO A REPRODUÇÃO E DIVULGAÇÃO TOTAL OU PARCIAL DESTE TRABALHO, POR QUALQUER MEIO CONVENCIONAL OU ELETRÔNICO, PARA FINS DE ESTUDO E PESQUISA, DESDE QUE CITADA A FONTE.

\section{FICHA CATALOGRÁFICA}

Arruda, Sigrid Lorena Batista

Manifestações clínicas e complicações associadas à toxoplasmose ocular. / Sigrid Lorena Batista Arruda; Orientador: João Marcello Fórtes Furtado; Coorientadora: Justine Ruth Smith. Ribeirão Preto, 2018.

75p.: 8il.; $30 \mathrm{~cm}$

Dissertação de Mestrado apresentada à Faculdade de Medicina de Ribeirão Preto/USP. Área de Concentração: Mecanismos Fisiopatológicos nos Sistemas Visual e ÁudioVestibular.

1. Toxoplasmose ocular. 2. Uveíte. 3. Retinite. 4. Toxoplasma gondii. 5. Uveíte posterior. 


\section{FOLHA DE APROVAÇÃO}

Aluno: Sigrid Lorena Batista Arruda

Título: Manifestações clínicas e complicações associadas à toxoplasmose ocular

Dissertação apresentada à Faculdade de Medicina de Ribeirão Preto da Universidade de São Paulo, para a obtenção do título de Mestre em Ciências.

Área de Concentração: Mecanismos Fisiopatológicos nos Sistemas Visual e ÁudioVestibular

Aprovado em:

Banca Examinadora

Prof. Dr.

Instituição:

Assinatura:

Prof. Dr.

Instituição:

Assinatura:

Prof. Dr.

Instituição:

Assinatura: 


\section{Dedicatória}

A Deus, por me abençoar e sempre me orientar a seguir o caminho do bem,

Aos melhores pais do mundo, Humberto e Ana, meus maiores incentivadores que, muitas vezes, doaram e renunciaram aos seus sonhos para que eu pudesse alcançar os meus,

À minha irmã e melhor amiga, Thaís, pelo seu amor incondicional e melhores lembranças da vida,

As minhas avós, Jovem, Emília e Mundica, por me fazerem sentir a pessoa mais sortuda do mundo e as ter presentes na primeira fileira de todas as minhas conquistas,

Ao meu amado marido, Mário, por me dar forças e palavras de apoio, quando achava que não conseguiria. Com você sou muito mais feliz, 


\section{Agradecimentos}

Ao Prof. Dr. João Marcello Fórtes Furtado, professor da Divisão de Oftalmologia da Faculdade de Medicina de Ribeirão Preto da Universidade de São Paulo e chefe do Serviço de Uveítes, pela oportunidade de realizar este estudo, sendo orientada por alguém a quem tenho grande admiração pessoal e profissional, tendo como sua maior qualidade a ética e o respeito com os demais profissionais e pacientes. Tenho orgulho em dizer que o senhor foi meu orientador.

À Profa. Dra. Justine Ruth Smith, coorientadora do projeto, que prontamente aceitou o convite, tornando o estudo ainda mais minucioso com a sua colaboração, vasta experiência, sabedoria, dedicação e humildade.

Ao Dr. Murilo Wendeborn Rodrigues Junior, grande amigo que esteve comigo desde o início quando ainda não sabíamos que este projeto acabaria virando uma Dissertação de Mestrado. Minha eterna gratidão pela sua amizade e sua admirável "mente brilhante".

À Dra. Milena Simões Freitas e Silva, fellow de uveite Hospital das Clínicas de da Faculdade de Medicina de Ribeirão Preto da Universidade de São Paulo, meu braço esquerdo, pela incansável e imprescindivel ajuda durante o último ano de desenvolvimento do projeto.

Ao Dr. Marlon Moraes Ibrahim, Dr. Marco Sérgio Pinto Alves Folgosa e Prof. Dr. Rubens Camargo Siqueira, pela colaboração no atendimento junto aos pacientes, sanando todas as dúvidas da propedêutica para cada caso apresentado. 
À Lucélia Albieri, técnica de enfermagem do Hospital das Clínicas de da Faculdade de Medicina de Ribeirão Preto da Universidade de São Paulo, pela ajuda na realização dos exames complementares dos participantes, além do imenso apoio emocional, que só quem tem o coração puro e fraterno consegue transmitir calmaria e paz nos piores momentos.

À Dra. Renata do Amaral Moreto Caravelas, Bárbara Regina Vieira e Michele Rodrigues de Araújo, minhas colaboradoras do projeto, sempre solícitas e empenhadas para a perfeita coleta de dados.

Ao Dr. Denny Marcos Garcia, responsável pela impecável análise estatística do projeto, meu agradecimento pela extrema educação, generosidade e por ser prestativo a cada pedido nosso.

Ao Roberto Fileto Junior e Andreia Gonçalves Baptista, pela ajuda na realização dos exames dos pacientes, sempre receptivos e perfeccionistas na qualidade dos exames.

À Maria Cecilia Onofre, secretária do Programa de Pós-graduação em Oftalmologia, Otorrinolaringologia e Cirurgia de Cabeça e Pescoço da Faculdade de Medicina de Ribeirão Preto da Universidade de São Paulo, por sempre estar acessivel às dúvidas burocráticas quanto ao funcionamento da pós-graduação, além de ter auxiliado com suas mãos de fada nas tenebrosas regras da ABNT.

Aos demais membros da secretaria do departamento de Oftalmologia pela receptividade e trabalho junto aos estudantes.

Aos residentes de oftalmologia e fellows de oftalmologia do serviço, que abraçaram o projeto junto comigo. 
Aos demais funcionários do Departamento de Oftalmologia, Otorrinolaringologia e Cirurgia de Cabeça e Pescoço, pela chance de realizar este estudo em uma grande instituição.

Aos participantes do estudo, que humildemente receberam toda a nossa equipe com carinho e respeito. Sem eles nada disso seria concretizado.

À Fundação de Apoio ao Ensino, Pesquisa e Assistência do Hospital das Clínicas da Faculdade de Medicina de Ribeirão Preto da Universidade de São Paulo (FAEPA-HCFMRP-USP) e ao Conselho Nacional de Desenvolvimento Científico e Tecnológico (CNPq) pelo apoio financeiro. (Proc. $\left.\mathrm{n}^{\circ} 400167 / 2016\right)$

À Fundação de Amparo à Pesquisa do Estado de São Paulo (FAPESP), pela concessão de bolsa de iniciação científica para a aluna colaboradora Michele Rodrigues de Araújo, (Proc. nº 2017/06680-4). 


\section{Epigrafe}

"Feliz aquele que transfere o que sabe e aprende o que ensina"

Cora Coralina 
Resumo 
ARRUDA, S. L. B. Manifestações clínicas e complicações associadas à toxoplasmose ocular. 75f. Dissertação (Mestrado). Faculdade de Medicina de Ribeirão Preto-USP. Ribeirão Preto-SP. 2018.

Neste estudo, foram descritos os aspectos clínicos e resultados visuais em indivíduos com evidência sorológica e sinais clínicos de toxoplasmose ocular. Os sujeitos foram examinados com lâmpada de fenda, exame de oftalmoscopia indireta, tendo registros fotográficos com retinografia e tomografia de coerência óptica. Duzentos e sessenta e sete participantes foram incluídos no estudo ( $n=350$ olhos). A forma de toxoplasmose ocular foi considerada primária em 52 indivíduos (19,5\%), recorrente ativa em $89(33,3 \%)$ e inativa em 126 (47,2\%). A maioria dos olhos apresentou uma lesão $(n=169 ; 48,3 \%)$, enquanto que 149 olhos $(42,6 \%)$ apresentaram duas a quatro lesões e 32 , cinco ou mais lesões $(9,1 \%)$. As lesões centrais estiveram presentes em 127 olhos (36,3\%), periféricas em 178 (50,9\%), enquanto que lesões centrais e periféricas em 45 (12,6\%). A maioria dos indivíduos apresentou sorologia para toxoplasma gondii (T. gondii) $\lg \mathrm{G}+\lg \mathrm{M}-(\mathrm{n}=245 ; 91,8 \%)$, enquanto que apenas $22(8,2 \%)$ foram $T$. gondii $\lg G+\lg M+$. Do total de olhos afetados em que a acuidade visual foi medida ( $n=314)$, a maioria $(n=160 ; 50,9 \%)$ apresentou melhor acuidade visual corrigida final $>20 / 40$, e $25,8 \%(n=81)$ foram considerados cegos (<20/400). Lesões múltiplas, de localização central e com tamanho maior que um diâmetro de disco óptico foram consideradas fator de risco para pior prognóstico visual. A membrana epirretiniana $(n=21 ; 7,1 \%)$ e opacidade vítrea $(n=20 ; 6,8 \%)$ foram as principais causas de complicações observadas. A taxa de incidência de complicações foi de 0,41 complicações/ano, e foram verificadas 0,13 reativações/ano. $O$ estudo demonstrou altas taxas de déficit visual, devendo ser realizados novos estudos para 0 desenvolvimento de novas modalidades terapêuticas para diminuir o impacto da doença como causa de cegueira e deficiência visual.

Palavras-chave: Toxoplasmose ocular. Uveíte. Retinite. Toxoplasma gondii. Uveíte posterior. 
Abstract 
ARRUDA, S. L. B. Clinical manifestations and complications associated with ocular toxoplasmosis. 75f. Dissertation (Masters). Ribeirao Preto Medical School, University of São Paulo, Ribeirao Preto-SP, 2018.

In this study, we describe the clinical aspects clinical aspects and visual outcomes in individuals with serological evidence and clinical signs of ocular toxoplasmosis. The subjects were examined with a slit lamp, indirect ophthalmoscopy examination, having photographic records with retinography and optical coherence tomography. Two hundred and sixty -seven subjects were included in the study ( $n=350$ eyes). The form of ocular toxoplasmosis was considered primary active in 52 subjects (19.5\%), recurrent active in 89 subjects (33.3\%) and inactive in 126 (47.2\%). Most eyes presented only one lesion ( $n=169 ; 48.3 \%)$, whereas 149 individuals $(42,6 \%)$ had $2-4$ lesions, and 32 had five or more lesions $(9.1 \%)$. Central lesions only were present in 127 eyes (36,3\%), peripheral in 178 (50,9\%\%), while concomitant central and peripheral were present in 45 (12.6\%). Most subjects had T. gondii IgG+ IgMserology $(n=245 ; 91.8 \%)$, whereas only $22(8,2 \%)$ were T. gondii IgG+ IgM+. From the total of affected eyes which visual acuity was measured $(n=314)$, most $(n=160$; $50,9 \%$ ) had better final corrected visual acuity> 20/40 and 25.8\% ( $n=81$ ) were considered blind $(<20 / 400)$. Multiple, centrally located lesions of greater size than an optic disc diameter were considered risk factor for a worse visual prognosis. The epiretinal membrane $(n=21 ; 7.1 \%)$ and vitreous opacity $(n=20 ; 6.8 \%)$ were the main causes of complications seen. The incidence rate of complications was 0,41 complications/year, and it was verified 0,13 reactivations/year. The study demonstrated a high rate of visual impairment, and studies for the development of novel therapeutic modalities should be performed to reduce the impact of the disease as a cause of blindness and visual impairment.

Keywords: Toxoplasmosis ocular. Uveitis. Retinitis. Toxoplasma gondii. Posterior uveitis. 
Lista de Figuras 
Figura 1: Lesão em atividade na periferia retiniana. Imagem da retinografia mostrando lesão hipocrômica, de aspecto cremoso, com bordas mal definidas (seta branca), associada à vitreîte, indicando atividade da doença

Figura 2: Lesões cicatrizadas e em atividade na periferia retiniana. Imagem da retinografia mostrando duas lesões cicatrizadas hiperpigmentadas na região superior (seta branca), com lesão hipocrômica adjacente e borda mal definida (seta vermelha), indicando atividade da doença

Figura 3: Lesão cicatrizada em região central macular do olho esquerdo de um participante do estudo. (A) Retinografia colorida do olho esquerdo evidenciando lesão de aspecto cicatricial com centro atrófico (branco-amarelado) e bordas bem definidas com hiperpigmentação. (B e C) Corte transversal do olho esquerdo feito pela tomografia de coerência óptica, da região da lesão cicatricial, apresentando diminuição da espessura retiniana, com desorganização das camadas retinianas

Figura 4: Tempo de acompanhamento dos participantes ao longo do estudo $(n=267)$

Figura 5: Relação de complicações oculares com 0 tempo de acompanhamento $\left(n=65\right.$ olhos $\left.^{*}\right)$

Figura 6: Taxa de incidência de complicações oculares ao longo do acompanhamento

Figura 7: Tempo decorrido para reativação por olho $(n=26)$ 50

Figura 8: Taxa de incidência de reativação associada com o tempo de acompanhamento 
Lista de Tabelas 
Tabela 1 - Características da amostra dos participantes com toxoplasmose ocular $(n=267)$

Tabela 2 - Achados da câmara anterior na admissão ( $\mathrm{n}=350$ olhos)

Tabela 3 - Número, localização e tamanho das lesões dos olhos diagnosticados com toxoplasmose ocular na admissão ( $n=350$ olhos)

Tabela 4 - Achados fundoscópicos na admissão ( $n=350$ olhos). 39

Tabela 5 - $\quad$ Acuidade visual dos participantes com lesão ativa na admissão e após a sua cicatrização $\left(\mathrm{n}=164\right.$ olhos $\left.^{*}\right)$

Tabela 6 - Acuidade visual dos pacientes com toxoplasmose inativa $\left(\mathrm{n}=150\right.$ olhos $\left.^{*}\right)$

Tabela 7 - Acuidade visual final dos pacientes com lesões cicatrizadas por toxoplasmose $(\mathrm{n}=314)$

Tabela 8 - Complicações associadas à toxoplasmose ocular ( $n=295$ olhos) ..... 43

Tabela 8.1 - Complicações associadas à toxoplasmose ocular na admissão ( $\mathrm{n}=14$ olhos)

Tabela 8.2 - Complicações associadas à toxoplasmose ocular durante o seguimento $\left(\mathrm{n}=51\right.$ olhos $\left.{ }^{*}\right)$

Tabela 9 - Fatores de risco associados à presença de complicação nos participantes com toxoplasmose ocular $(n=295)$

Tabela 10 - Correlação entre profilaxia versus recidiva ......................................51

Tabela 11 - Comparação de estudos clínicos sobre toxoplasmose ocular 58 
Lista de Abreviaturas 
AV- $\quad$ Acuidade visual

HCFMRP-USP- Hospital das Clínicas da Faculdade de Medicina de Ribeirão Preto da Universidade de São Paulo

HIV- Vírus da imunodeficiência humana

OD- Olho direito

OE- $\quad$ Olho esquerdo

PCR- Reação em cadeia da polimerase

T. gondii- Toxoplasmagondii 


\section{SUMÁRIO}

1- INTRODUÇÃO

2- JUSTIFICATIVA

3- OBJETIVOS

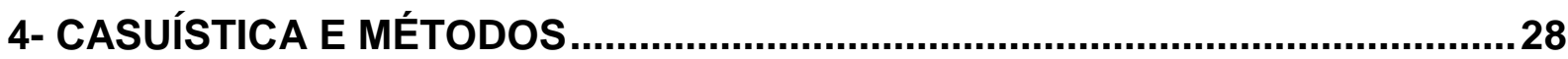

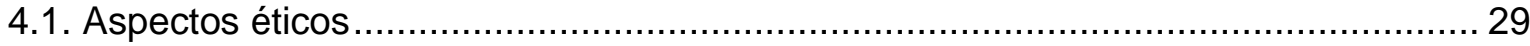

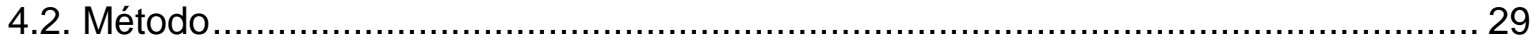

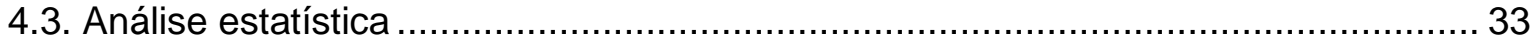

5- RESULTADOS

6- DISCUSSÃO

7- CONCLUSÕES

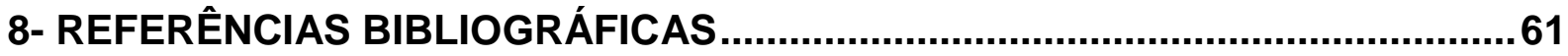

9- ANEXOS 


\section{1- Introdução}


A toxoplasmose acomete aproximadamente um terço da população mundial, e é causada pelo protozoário Toxoplasma gondii ( $T$. gondii), um dos parasitas com distribuição mais ampla no mundo. ${ }^{1}$ O T. gondii foi descrito, originalmente, em 1908, e é transmitido principalmente por via oral, por meio da ingestão de carne contendo cistos do parasita ou de água contaminada com oocistos liberados nas fezes de felinos. ${ }^{2}$ Também pode ser transmitido de maneira vertical, quando a mulher adquire a doença durante a gravidez, ${ }^{3}$ ou mais raramente, por meio de transplante de órgãos. ${ }^{4}$

O olho é o órgão mais frequentemente acometido em indivíduos previamente saudáveis, levando à inflamação da retina e coroide (retinocoiroidite). É a infecção pelo taquizoíta, a forma do $T$. gondii que se divide rapidamente, e que caracteriza a fase aguda da doença. A ação direta do parasita e também a reação inflamatória criada para combater a infecção causam lesões retinianas que podem levar à cegueira. $^{5}$

Indivíduos imunocompetentes, que adquirem a doença após o nascimento, geralmente são assintomáticos, mas em imunodeprimidos a doença, frequentemente, se manifesta como encefalite e pode ser fatal. ${ }^{1}$ Outro fator observado, é que a toxoplasmose ocular pode se desenvolver vários anos após a infecção sistêmica inicial. ${ }^{6}$

Desde a década de 50 , a toxoplasmose é descrita como uma forma de doença inflamatória ocular decorrente da infecção intraocular pelo T. gondii. Atualmente, a toxoplasmose ocular é uma das principais causas mundiais de uveíte posterior, e o risco de infecção e envolvimento ocular variam nas diversas regiões do mundo. ${ }^{7}$

Antigamente, acreditava-se que pacientes que apresentavam toxoplasmose ocular haviam sido infectados intraútero, e que lesões oculares diagnosticadas em idade adulta seriam manifestações tardias de infecção congênita. ${ }^{8}$ Mas um importante estudo de coorte realizado em Erechim-RS evidenciou que grande parte dos indivíduos que apresentam anticorpos contra o parasita se infectou ao longo da vida. $^{9,10}$

Até o momento, não se sabe ao certo quais são os fatores relacionados à ocorrência, gravidade e recorrência da doença ocular, embora haja vários indícios 
que sugerem que o estado nutricional, a susceptibilidade genética, o genótipo do parasita e a carga parasitária estejam envolvidos nessa infecção. ${ }^{11} \mathrm{O}$ estado imunológico do hospedeiro é claramente importante, como demonstrado pelo curso de doença grave e prolongada em pacientes imunossuprimidos. ${ }^{12}$

A retina é o tecido ocular mais acometido pelo $T$. gondii, sendo que outros tecidos também podem ser acometidos, como, por exemplo, a coroide. ${ }^{13-16}$

Os principais sintomas da toxoplasmose ocular são: turvação visual, hiperemia e fotofobia. A baixa da visão central, podendo evoluir para a perda da mesma, ocorre quando a toxoplasmose está associada ao envolvimento da mácula, que pode persistir, mesmo após a cicatrização da lesão. ${ }^{17}$

A apresentação clássica na toxoplasmose adquirida é de uma área bem demarcada de necrose coagulativa com coroidite adjacente, podendo ter vasculite, hemorragia e vitreíte. Os taquizoítos e os cistos teciduais podem ser encontrados em todas as camadas da retina infectada, em conjunto com uma reação celular inflamatória mononuclear intensa local, assim como na coroide e no vítreo adjacente. $^{12}$

O Brasil apresenta elevada prevalência de toxoplasmose, as taxas de infecção variam de $50 \%$ a $83 \%$ da população, dependendo da localização do estudo. $^{8,18,19}$ A prevalência e gravidade de lesões oculares também são mais elevadas no Brasil do que em outros países. No Japão, uma pesquisa envolvendo quarenta e um hospitais, revelou que a infecção por $T$. gondii, não era a principal causa de uveíte, sendo responsável por apenas $1,1 \%$ de todos os casos. ${ }^{1}$ Nos Estados Unidos, aproximadamente $2 \%$ das infecções por T. gondii progridem para toxoplasmose ocular, enquanto que no sul do Brasil, a proporção pode chegar a 18\%. ${ }^{1,8}$ Apesar de existirem poucos estudos populacionais de prevalência e incidência de toxoplasmose ocular na literatura, ${ }^{20}$ este número é extremamente elevado quando comparado a outros países, como por exemplo, em Gana, onde se estima que $2,6 \%$ da população apresentem lesões oculares decorrentes do parasita, ${ }^{21}$ e nos Estados Unidos, estima-se que, anualmente, aproximadamente 21 mil pessoas $(0,0065 \%$ da população) apresentem primeiro episódio de toxoplasmose ocular, sendo que em 4.800 dessas pessoas desenvolvem coriorretinite sintomática. $^{22}$ 
No Brasil, existem também maiores índices de infecção congênita e de lesões oculares em neonatos infectados intraútero. ${ }^{23}$ Quando comparados com os casos de toxoplasmose congênita na Europa, pacientes infectados no Brasil apresentam pior prognóstico ocular, ${ }^{24} \mathrm{e}$ a doença é uma das causas frequentes de cegueira infantil no Brasil. ${ }^{25,26}$

Estudos realizados no Brasil, em ambiente hospitalar utilizando pequenas amostras, revelaram que na metrópole de São Paulo, a identificação de anticorpos de $T$. gondii em gestantes pode variar de $59 \%$ a $65 \% .{ }^{27,28} \mathrm{Um}$ estudo realizado em 1990, na cidade de Erechim-RS, mostrou que a soropositividade para toxoplasmose chega a aproximadamente $88 \%$; sendo que $18 \%$ desenvolveram toxoplasmose ocular. $^{9}$

Apesar dos dados serem limitados em relação à epidemiologia deste agravo, acredita-se que os hábitos alimentares, fatores culturais como economia baseada na agricultura, resposta imunológica ao parasita, características genéticas do hospedeiro e características genéticas das cepas de $T$. gondii podem estar relacionadas com a elevada prevalência e gravidade de lesões oculares relacionadas à toxoplasmose no Brasil. ${ }^{29}$

Entre as complicações, a mais temida é a baixa da acuidade visual (AV) do olho acometido, podendo levar à perda de visão parcial ou até mesmo cegueira. ${ }^{14,30}$ Em um estudo realizado, a ocorrência de comprometimento grave da visão no olho afetado foi observada em $17,4 \%$ dos participantes, uma incidência ligeiramente menor de cegueira quando comparada a outras séries de casos. ${ }^{31,32}$ Outro estudo brasileiro que analisou as causas de baixa AV, observadas em um serviço de visão subnormal, demonstrou que $89 \%$ da deficiência visual dos participantes dentro das etiologias das uveítes foram causados pela toxoplasmose ocular. ${ }^{33}$ Como esperado, comprometimento visual grave foi associado à localização das lesões retinocoroidais maculares, recorrência e ocorrência de complicações. 
2. Justificativa 
A toxoplasmose ocular é a principal causa mundial de uveíte posterior, ${ }^{7}$ e uma das principais causas de cegueira infantil no Brasil. ${ }^{25}$ Apesar disso, existem poucos estudos prospectivos que analisam o padrão de lesões oculares, fatores de risco para o desenvolvimento de complicações, recidivas e deficiência visual associada à doença. Além disso, o estudo de referência sobre lesões oculares em pacientes com toxoplasmose ocular é retrospectivo e realizado na Europa, ${ }^{32}$ o que não necessariamente se aplica à realidade brasileira, pois acredita-se que a prevalência e gravidade das lesões oculares em pacientes com toxoplasmose são maiores na América Latina do que nas demais regiões do mundo. ${ }^{20}$ 
3. Objetivos 
Os objetivos deste estudo prospectivo foram:

Analisar as manifestações clínicas da toxoplasmose ocular em relação a: número de lesões, recorrência, lateralidade, complicações clínicas e fatores associados à deficiência visual e cegueira;

Comparar as variáveis mencionadas no item acima, de acordo com sexo, cor de pele autodeclarada, idade, forma de contágio e diferentes padrões de sorologias encontradas;

Analisar a incidência de complicações e reativações do quadro ocular nos participantes seguidos ao longo do tempo. 
4. Casuistica e Métodos 
Estudo de série de casos, realizado no Ambulatório do Setor de Uveítes da Divisão de Oftalmologia do Hospital das Clínicas de Ribeirão Preto da Faculdade de Medicina de Ribeirão Preto da Universidade de São Paulo (HCFMRP-USP), com diagnóstico de toxoplasmose ocular, atendidos no período de abril de 2015 a julho de 2017.

\subsection{Aspectos éticos}

O protocolo de pesquisa foi aprovado pelo Comitê de Ética em Pesquisa do HCFMRP-USP (no 46015415.2.0000.5440) (Anexo A).

Foram incluídos no estudo indivíduos com lesões oculares sugestivas de toxoplasmose e sorologia compatível para a mesma, que concordaram em participar da pesquisa e assinaram o Termo de Consentimento Livre e Esclarecido (Anexo B). Os menores de 18 anos, somente com o aceite e assinatura do termo por seu responsável legal.

\subsection{Método}

Para o presente estudo, o diagnóstico de toxoplasmose ocular foi feito com base na visualização de lesões retinianas sugestivas de toxoplasmose, já descritas na literatura, ${ }^{5}$ na ausência de outras possíveis causas, aliada à presença de sorologia positiva antitoxoplasma lgG e/ou lgM. As lesões foram consideradas ativas na presença de aspecto brancacento, mal delimitadas, associadas ou não à exsudação vítrea (Figura 1). As lesões cicatrizadas podiam se apresentar de cinco formas diferentes: a) lesão bem delimitada com halo hiperpigmentado e centro atrófico (Figura 2); b) lesão bem delimitada com traços de hiperpigmentação central entremeando a atrofia central; c) lesão bem delimitada com halo claro, porém com hiperpigmentação central; d) lesão hipopigmentada bem delimitada nas bordas, sugerindo atrofia do epitélio pigmentar retiniano; e) lesão hiperpigmentada e bem delimitada. ${ }^{5}$

As variáveis estudadas foram: sexo, idade, cor da pele autodeclarada, forma de aquisição da toxoplasmose (congênita, adquirida pós-natal e indeterminada), 
tratamento realizado antes da admissão do estudo, lateralidade (olho direito, esquerdo, ou ambos), AV melhor corrigida, sorologia antitoxoplasma lgG e IgM, número, tamanho, localização das lesões retinianas (central - macular, adjacente ao nervo óptico, entre as arcadas e periféricas) causadas pelo $T$. gondii, uso de antibioticoterapia profilática e complicações relacionadas. Nos casos de lesões atípicas (toxoplasmose ativa bilateral, extensas e/ou multifocais) foi realizada a coleta de material intraocular para avaliação do PCR (reação em cadeia da polimerase).

A coleta de dados foi realizada por médicos oftalmologistas devidamente treinados sob a coordenação do chefe do Ambulatório de Uveítes do HCFMRP-USP. O diagnóstico foi realizado por especialistas em uveíte baseados na verificação das lesões sugestivas de toxoplasmose no fundo de olho, associados à confirmação sorológica. Os dados foram obtidos a partir da anamnese e do exame físico dos participantes do estudo, anotados em dois formulários de coletas de dados: um de admissão (Anexo C) e outro referente ao retorno (Anexo D).

O exame oftalmológico incluiu a medida da AV inicial com buraco estenopeico em todas as consultas, realizado pelos residentes de oftalmologia, com tabela de optotipos a quatro metros, biomicroscopia do segmento anterior, tonometria, oftalmoscopia indireta sob midríase e exames complementares (retinografia e tomografia de coerência óptica). A biomicroscopia do segmento anterior, realizada pela lâmpada de fenda, tinha o intuito de observar as possíveis alterações presentes na admissão, como reação de câmara anterior, precipitados ceráticos, sinéquias posteriores, catarata, vitreíte anterior, entre outros. A tonometria foi aferida em todos os participantes com o tonômetro de aplanação Goldmann, em todas as consultas.

O fundo de olho do participante foi documentado em todas as consultas por meio de imagem fotográfica realizada por retinógrafo não midriático (Canon CR2 Non-Mydriatic Retinal Camera, Melville, Nova lorque, Estados Unidos da América) nas lesões centrais da retina e em pupilas com dificuldade de dilatação; e midriático (Topcom TRC-50DX, Oakland, Nova Jersey, Estados Unidos da América) nas lesões periféricas; sendo que em alguns casos, quando as lesões estavam em extrema periferia, somente foi feita a análise visual da lesão com oftalmoscópio indireto. Complementando o exame, foram obtidas imagens das lesões no momento do 
primeiro atendimento com Tomografia de Coerência Óptica (Heidelberg Spectralis HRA \& OCT, Franklin, Massachusetts, Estados Unidos da América), tanto em lesões ativas quanto cicatrizadas, e novamente no retorno dos pacientes com lesão ativa anteriormente e que apresentaram, no segundo momento, a cicatrização das mesmas. Nos casos de lesões em extrema periferia, de participantes recémnascidos e/ou lactentes, o exame não foi realizado. O número de lesões retinianas foi verificado na oftalmoscopia indireta e o tamanho das mesmas estimado em diâmetro de discos ópticos.

Para este estudo, o diagnóstico da toxoplasmose foi baseado na pesquisa de Bosch-Drissen et al. $^{32}$, sendo dividido em: toxoplasmose ocular primária (retinocoroidite focal, exsudativa, branca cremosa, não associada a cicatrizes retinocoroidais - Figura 1), toxoplasmose ocular ativa e recorrente (retinocoroidite focal, ativa, associada à cicatrização retiniana no mesmo olho ou no olho contralateral - Figura 2), toxoplasmose ocular inativa e recorrente (presença de cicatrizes retinianas, sem lesão ativa - Figura 3) e indeterminada, quando não se encaixava em nenhuma das classificações supracitadas. Quanto à aquisição da infecção, ela foi dividida em toxoplasmose ocular congênita (adquirida durante a gestação), adquirida pós-natal e indeterminada (quando não era possível se determinar a forma exata de aquisição da infecção) ${ }^{32}$. Em relação à classificação da localização das lesões, elas poderiam ser: central, subdividida em macular, adjacente ao nervo óptico ou outra, e periférica.

As complicações foram classificadas de acordo com os achados dos exames realizados nos retornos dos participantes: biomicroscopia, tonometria e oftalmoscopia indireta. Entre as complicações é possível citar: opacidade vítrea persistente (presente por mais de três meses após cicatrização das lesões), glaucoma, hipertensão intraocular, atrofia óptica, membrana epirretiniana, edema macular, neovasos de retina e coroide, descolamento regmatogênico de retina e oclusão venosa, entre outros. 
Figura 1 - Lesão em atividade na periferia retiniana. Imagem da retinografia mostrando lesão hipocrômica, de aspecto cremoso, com bordas mal definidas (seta branca), associada à vitreíte, indicando atividade da doença

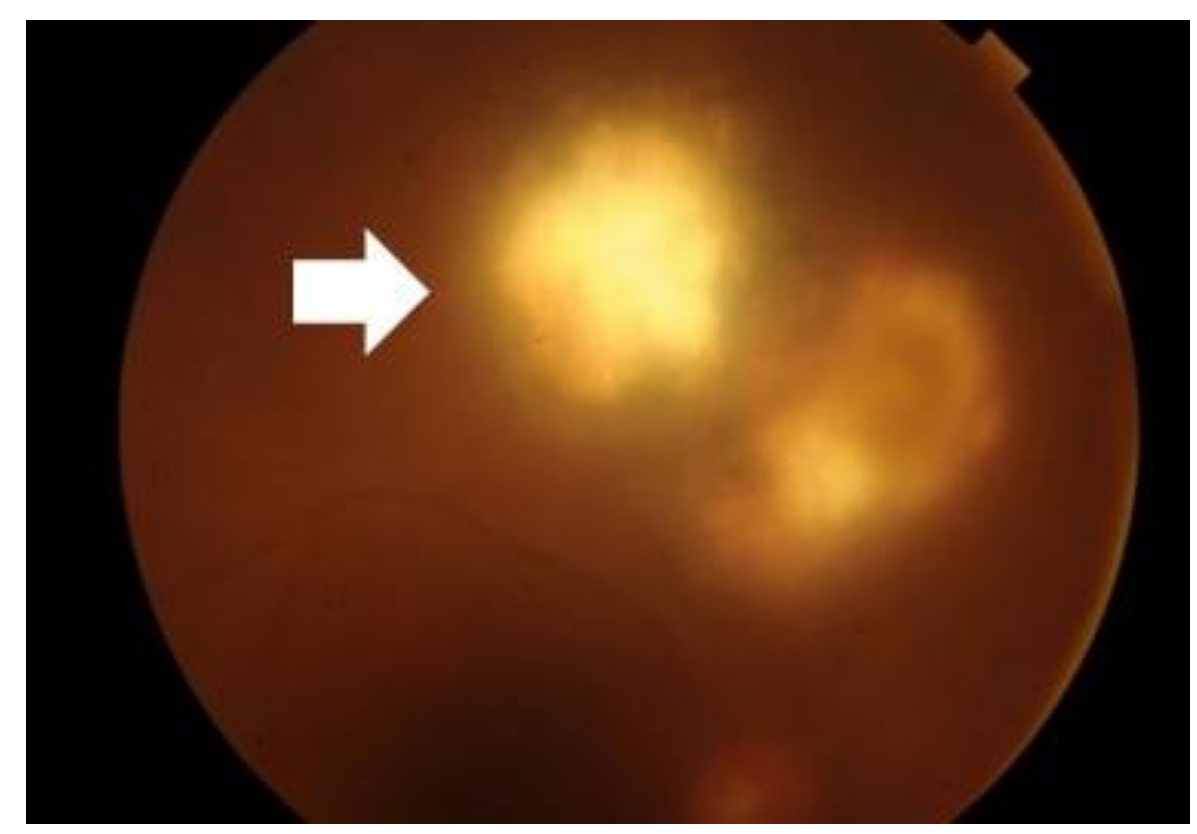

Figura 2 - Lesões cicatrizadas e em atividade na periferia retiniana. Imagem da retinografia mostrando duas lesões cicatrizadas hiperpigmentadas na região superior (seta branca), com lesão hipocrômica adjacente e borda mal definida (seta vermelha), indicando atividade da doença

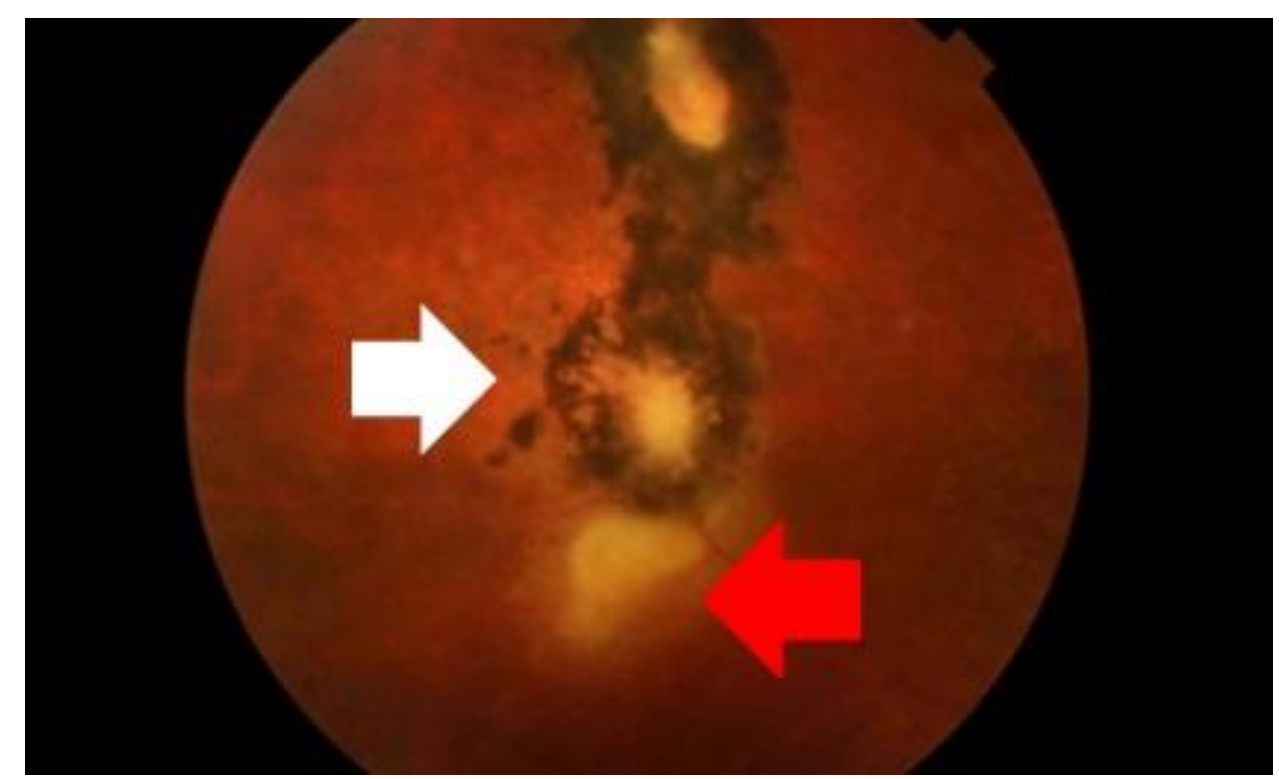


Figura 3 - Lesão cicatrizada em região central macular do olho esquerdo de um participante do estudo. (A) Retinografia colorida do olho esquerdo evidenciando lesão de aspecto cicatricial com centro atrófico (branco-amarelado) e bordas bem definidas com hiperpigmentação. (B e C) Corte transversal do olho esquerdo feito pela tomografia de coerência óptica, da região da lesão cicatricial, apresentando diminuição da espessura retiniana, com desorganização das camadas retinianas
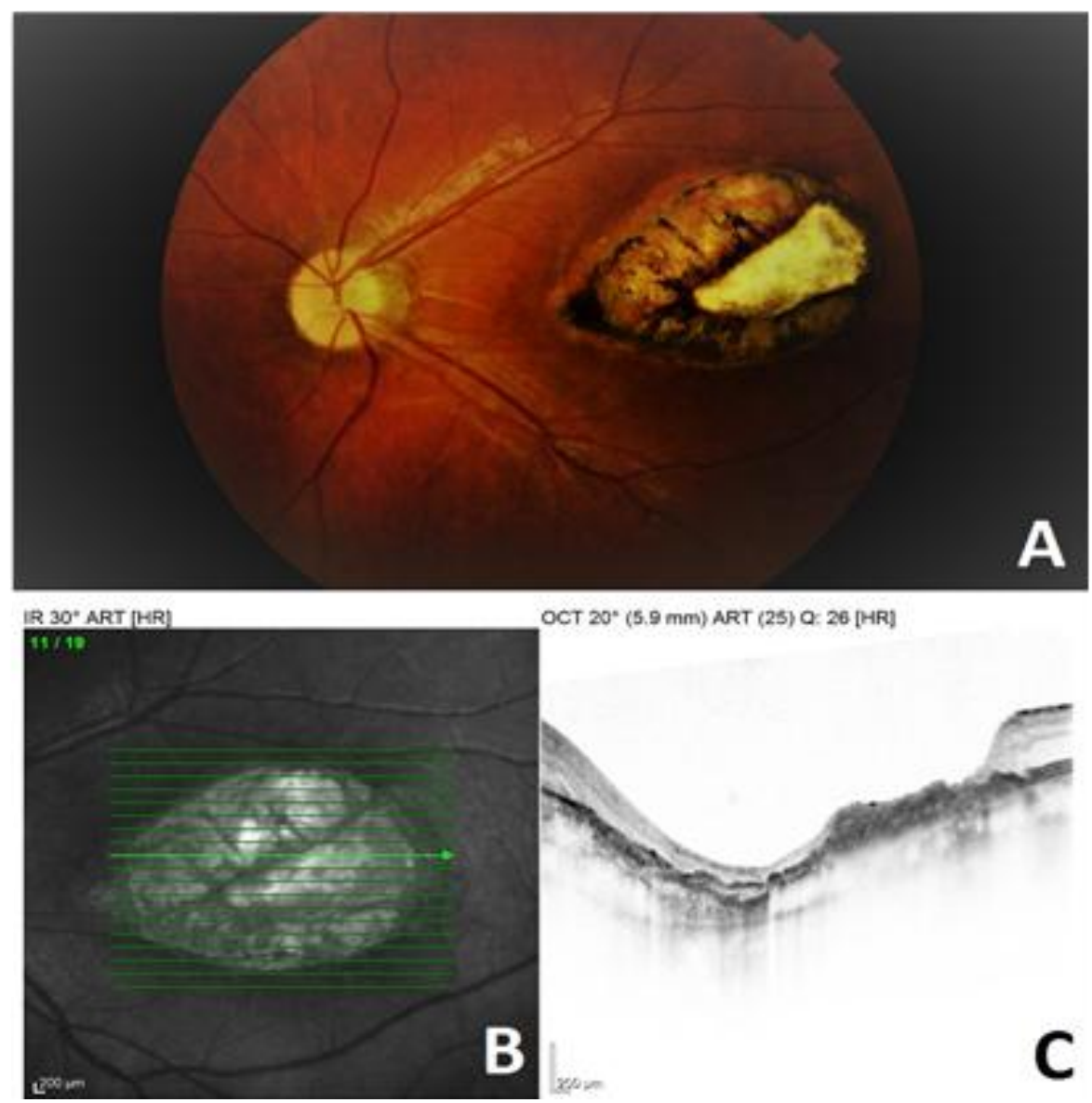

\subsection{Análise estatística}

As variáveis estudadas foram comparadas por participante e por grupo de participantes, incluindo: sexo, faixa etária, cor da pele autodeclarada, diagnóstico (primária, recorrente ativa, recorrente inativa ou indeterminada), forma de contágio da doença (congênita, adquirida pós-natal, ou indeterminada), sorologia, início e curso da doença, olho acometido, número e localização das lesões, número de recorrências, complicações, profilaxia e AV final). 
As diferenças entre proporções nos diversos grupos foram comparadas por: teste qui quadrado para amostras independentes e teste McNemar para amostras pareadas. Foram considerados resultados significativos quando $p<0.05$. 
5. Resultados 
Participaram deste estudo 267 indivíduos (350 olhos acometidos) (Tabela 1), sendo 143 do sexo feminino e 124 do sexo masculino, com idades variando de 0 a 86 anos (média $=36,6$ anos, desvio padrão=16,9). Cento e vinte e seis participantes se autodeclararam pardos (47,2\%), 102 brancos (38,2\%), 36 negros $(13,5 \%)$ e três $(1,1 \%)$ não sabiam definir a sua cor de pele. Quanto à origem da infecção, a maior parte dos casos (230 participantes, 86,1\%) foi indeterminada, seguida de toxoplasmose congênita (24 participantes, 9\%), e em menor número toxoplasmose adquirida pós-natal (13 participantes, 4,9\%). No início do estudo, 126 participantes $(47,2 \%)$ receberam diagnóstico de toxoplasmose recorrente inativa, 89 intitulados com toxoplasmose recorrente ativa $(33,3 \%)$ e apenas 52 com toxoplasmose primária $(19,5 \%)$.

Em relação ao tratamento, a maior parte dos pacientes $(57,7 \%)$ havia recebido tratamento com Sulfametoxazol, Trimetoprim e corticoide associado (153 participantes), seguido de 52 participantes (19,6\%) nunca tratados anteriormente, 39 $(14,7 \%)$ receberam Sulfametoxazol com Trimetoprim e 15 (5,7\%) foram classificados como outros tipos de regimes terapêuticos, utilizando medicações de segunda escolha, ou realizando a troca de medicações quando a resposta terapêutica não estava sendo satisfatória (ex: a troca do por Sulfametoxazol com Trimetoprim e viceversa). Seis participantes afirmavam terem sido tratados, mas não souberam o nome das medicações usadas $(2,3 \%)$ (Tabela 1$)$. Seis participantes, ao longo do tratamento, apresentaram efeitos colaterais à medicação: quatro com farmacodermia, um com intolerância gástrica e um com alterações de enzimas hepáticas. Uma paciente ficou grávida durante o tratamento, sendo necessário trocar a medicação. A sorologia prevalente foi de $\operatorname{lgM}-\lg G+$ em 243 participantes, seguidos de $\operatorname{lgM}^{+} \operatorname{lgG}{ }^{+}$em 22 e dois com $\operatorname{lgM}$ indeterminado com $\operatorname{lgG}^{+}$, nos quais a sorologia foi repetida no retorno, com resultado de IgM-lgG+ (Tabela 1). A forma clínica típica estava presente em 258 participantes, e em somente nove a doença ocular foi classificada como atípica (toxoplasmose ativa bilateral, extensa e/ou multifocail (Tabela 1). Cinco participantes do grupo dos atípicos tiveram toxoplasmose ocular confirmada pela análise do PCR após coleta de material intraocular. 
Tabela 1 - Características da amostra dos participantes com toxoplasmose ocular $(n=267)$

\begin{tabular}{|c|c|}
\hline Variáveis & $\mathbf{N}(\%)$ \\
\hline \multicolumn{2}{|l|}{ Sexo: } \\
\hline Masculino & $124(46,4)$ \\
\hline Feminino & $143(53,6)$ \\
\hline \multicolumn{2}{|l|}{ Idade (anos): } \\
\hline$\leq 17$ & $239(10,9)$ \\
\hline $18-64$ & $214(80,1)$ \\
\hline$\geq 65$ & $24(0,9)$ \\
\hline \multicolumn{2}{|l|}{ Cor de pele autodeclarada: } \\
\hline Branca & $102(38,2)$ \\
\hline Parda & $126(47,2)$ \\
\hline Negra & $36(13,5)$ \\
\hline Não sabe & $3(1,1)$ \\
\hline \multicolumn{2}{|l|}{ Diagnóstico: } \\
\hline Primária & $52(19,5)$ \\
\hline Recorrente (Ativa) & $89(33,3)$ \\
\hline Recorrente (Inativa) & $126(47,2)$ \\
\hline \multicolumn{2}{|l|}{ Aparência clínica } \\
\hline Típica & $258(96,6)$ \\
\hline Atípica & $9(3,4)$ \\
\hline \multicolumn{2}{|l|}{ Origem: } \\
\hline Congênita & $24(9,0)$ \\
\hline Adquirida pós-natal & $13(4,9)$ \\
\hline Indeterminado & $230(86,1)$ \\
\hline \multicolumn{2}{|l|}{ Resultado sorológico: } \\
\hline Toxoplasma gondii $\lg \mathrm{G}+\lg \mathrm{M}+$ & $22(8,2)$ \\
\hline Toxoplasma gondii lgG+ IgM- & $243(91,0)$ \\
\hline Toxoplasma gondii lgG- IgM+ & $0(0,0)$ \\
\hline Toxoplasma gondii IgG+ IgM Indeterminado & $2^{*}(0,8)$ \\
\hline \multicolumn{2}{|l|}{ Tratamento: } \\
\hline Nunca tratou & $52(19,6)$ \\
\hline Sulfadiazina e Pirimetamina & $39(14,7)$ \\
\hline Sulfametoxazol e Trimetoprim & $153(57,7)$ \\
\hline Tratou, mas não sabe o nome & $6(2,3)$ \\
\hline Outros & $17(5,7)$ \\
\hline
\end{tabular}

$\mathbf{N}=$ número de participantes; ${ }^{*}$ no retorno do participante a sorologia repetida, tendo como resultado Toxoplasma gondii lgG+ IgM-.

$\mathrm{Na}$ análise dos achados da câmara anterior, não foram observadas alterações na maioria dos participantes (72\%). Reação de câmara anterior (presença de 
celularidade no humor aquoso) associada ou não a precipitados ceráticos (conglomerados de células inflamatórias que se depositam no endotélio corneano) foi a alteração mais frequente (Tabela 2).

Tabela 2 - Achados da câmara anterior na admissão ( $n=350$ olhos)

\begin{tabular}{lc}
\hline \multicolumn{1}{c}{ Câmara anterior $\left(^{*}\right)$} & N (\%) \\
\hline Ausência de alterações & $252(72,0)$ \\
Reação de câmara anterior & $37(10,6)$ \\
Reação de câmara anterior e precipitados ceráticos & $24(6,9)$ \\
Catarata & $11(3,1)$ \\
Somente precipitados ceráticos & $10(2,9)$ \\
Reação de câmara anterior, precipitados ceráticos, vitreíte anterior, & $8(2,3)$ \\
sinéquia posterior & $6(1,7)$ \\
Sinéquia posterior & $3(0,9)$ \\
Outros & $2(0,6)$ \\
Vitreíte anterior &
\end{tabular}

A maioria dos olhos apresentou lesões únicas (48,3\%), com localização periférica $(50,9 \%)$ e diâmetro maior que um tamanho de disco óptico (82\%) (Tabela $3)$. 
Tabela 3 - Número, localização e tamanho das lesões dos olhos diagnosticados com toxoplasmose ocular na admissão ( $\mathrm{n}=350$ olhos)

\begin{tabular}{lc}
\hline \multicolumn{1}{c}{ Variáveis } & $\mathbf{N}(\%)$ \\
\hline Número de lesões: & $169(48,3)$ \\
1 & $149(42,6)$ \\
$2-4$ & $32(9,1)$ \\
$\geq 5$ & \\
Localização das lesões: & $178(50,9)$ \\
Periférica & $65(18,6)$ \\
Central macular & $62(17,7)$ \\
Central outra & $45(12,6)$ \\
Central e periférica & \\
Tamanho das lesões: & $63(18,0)$ \\
$<1$ diâmetro de disco óptico & $287(82,0)$ \\
$>1$ diâmetro de disco óptico &
\end{tabular}

$\mathbf{N}=$ número de olhos acometidos.

Os achados do pólo posterior, no momento da admissão, evidenciaram, em sua maioria, a presença de cicatriz de coriorretinite, associada com hiperpigmentação do epitélio pigmentar da retina, ambas em $82,9 \%$ dos olhos, seguidas de lesões ativas (39,7\%) e vitreíte (22\%) (Tabela 4).

Tabela 4 - Achados fundoscópicos na admissão ( $n=350$ olhos)

\begin{tabular}{lc}
\hline \multicolumn{1}{c}{ Segmento posterior $\left(^{*}\right)$} & $\mathbf{N}(\%)$ \\
\hline Cicatriz de coriorretinite & $290(82,9)$ \\
Hiperpigmentação do epitélio pimentar da retina & $290(82,9)$ \\
Lesão ativa & $139(39,7)$ \\
Vitreíte & $77(22,0)$ \\
Vasculite & $17(4,9)$ \\
Papilite & $4(1,1)$ \\
Membrana epirretiniana & $2(0,6)$ \\
Edema macular & $1(0,3)$ \\
Neovasos de coroide & $1(0,3)$ \\
Neovasos retinianos & $0(0,0)$ \\
Descolamento seroso & $2(0,6)$ \\
Descolamento regmatogênico & $0(0,0)$ \\
Oclusão de veia central da retina & $1(0,3)$ \\
Hemorragia retiniana perilesional & $1(0,3)$ \\
Outros & $1(0,3)$ \\
\hline N= número de olhos acometidos com complicações. $\left(^{*}\right)$ 319 olhos $(91,1 \%)$ apresentaram \\
mais de um achado
\end{tabular}


A AV, tanto inicial quanto final, foi testada em todos os olhos acometidos, de forma monocular, sendo avaliada em dois grupos: os com lesão ativa no momento da admissão e após a cicatrização (toxoplasmose primária ou recorrente ativa); e os com lesões cicatrizadas (toxoplasmose recorrente inativa). O grupo com lesões ativas apresentou melhoria da AV significativa após o tratamento, sendo a maioria dos olhos classificada com visão normal, AV $>20 / 40$, em 57,9\% dos olhos acometidos (Tabela 5). O grupo que na admissão já apresentava lesão cicatrizada (Tabela 6) não evidenciou diferença estatística significativa $(p=0,7504)$, mantendo a visão normal na maioria dos olhos (43,3\%). Sete participantes (2,2\%) foram considerados cegos bilateralmente. Vale ressaltar que foi impossível aferir a AV de 36 participantes, por alguns apresentarem dificuldade cognitiva ou serem lactentes/recém-nascidos.

Tabela 5 - Acuidade visual dos participantes com lesão ativa na admissão e após a sua cicatrização ( $\mathrm{n}=164$ olhos*)

\begin{tabular}{lcc}
\hline \multirow{2}{*}{ Acuidade Visual } & Admissão & Última consulta \\
\cline { 2 - 3 } & $\mathbf{N}(\%)$ & $\mathbf{N}(\%)$ \\
\hline Visão normal (> 20/40) & $68(41,5)$ & $95(57,9)$ \\
Deficiência visual leve (20/40 a 20/63) & $18(11,0)$ & $13(7,9)$ \\
Deficiência visual moderado (<20/63 a 20/200) & $27(16,5)$ & $19(11,6)$ \\
Deficiência visual grave (<20/200 a 20/400) & $2(1,2)$ & $0(0,0)$ \\
Cegueira $(<20 / 400)$ & $49(29,9)$ & $37(22,6)$ \\
\hline
\end{tabular}

Foram excluídos participantes com déficit cognitivo e/ou idade pré-verbal, além dos que foram vistos somente uma vez.

Tabela 6 - Acuidade visual dos pacientes com toxoplasmose inativa ( $n=150$ olhos $\left.{ }^{\star}\right)$

\begin{tabular}{lc}
\hline \multicolumn{1}{c}{ Acuidade Visual } & $\mathbf{N}(\%)$ \\
\hline Visão normal $(>20 / 40)$ & $65(43,3)$ \\
Déficit visual leve (20/40 a 20/63) & $13(8,7)$ \\
Déficit visual moderado $(<20 / 63$ a 20/200) & $28(18,7)$ \\
Déficit visual grave $(<20 / 200$ a 20/400) & $0(0,0)$ \\
Cegueira $(<20 / 400)$ & $44(29,3)$ \\
\hline
\end{tabular}

*Excluídos participantes com déficit cognitivo e/ou idade pré-verbal. 
Outra análise realizada foi a comparação da AV final de 314 olhos com lesões cicatrizadas em relação a: sexo, idade, cor da pele autodeclarada, origem da infecção, localização das lesões retinianas, número e tamanho das lesões, além do tratamento instituído (Tabela 7). Cada olho teve a AV final categorizada em: $A V>20 / 200$ ou $A V \leq 20 / 200$. Em cinco itens (sexo, idade, cor da pele autodeclarada, origem da infecção e tratamento) não foram encontradas diferenças estatísticas significativas $(p \leq 0,05)$. Os olhos com uma lesão apresentaram melhor AV em relação àqueles com múltiplas lesões (casos recorrentes), com valor de $p<0,0001$. Além disso, foi constatado que os olhos que apresentavam somente lesões periféricas $(p<0,001)$ e menores de um diâmetro de tamanho de disco óptico $(p=0,0036)$, tinham melhor AV (Tabela 7). 
Tabela 7 - Acuidade visual final dos pacientes com lesões cicatrizadas por toxoplasmose $(n=314)$

\begin{tabular}{|c|c|c|c|}
\hline \multirow{2}{*}{ Fator } & \multicolumn{2}{|c|}{ Acuidade Visual Final Categorizada } & \multirow{2}{*}{ p - Valor } \\
\hline & $A V \geq 20 / 200(n=233)$ & $A V<20 / 200(n=81)$ & \\
\hline \multicolumn{4}{|l|}{ Sexo } \\
\hline Feminino & 131 & 39 & 0,209 \\
\hline Masculino & 102 & 42 & \\
\hline \multicolumn{4}{|l|}{ Idade } \\
\hline$\leq 17$ & 13 & 6 & 0,7305 \\
\hline $18-64$ & 201 & 67 & \\
\hline$\geq 65$ & 19 & 8 & \\
\hline \multicolumn{4}{|l|}{ Cor de pele } \\
\hline Branca & 85 & 34 & 0,5461 \\
\hline Parda & 115 & 34 & \\
\hline Preta & 32 & 10 & \\
\hline \multicolumn{4}{|l|}{ Origem } \\
\hline Primária & 38 & 14 & 0,2679 \\
\hline Recorrente Ativa & 89 & 23 & \\
\hline Recorrente Inativa & 106 & 44 & \\
\hline \multicolumn{4}{|l|}{ Localização } \\
\hline Periférica & 138 & 23 & $<0,0001$ \\
\hline Central macular & 26 & 24 & \\
\hline Central outra & 49 & 11 & \\
\hline Central e periférica & 20 & 23 & \\
\hline \multicolumn{4}{|l|}{ Tratamento } \\
\hline Nunca tratou & 40 & 17 & 0,8338 \\
\hline Sulfadiazina e Pirimetamina & 27 & 7 & \\
\hline Sulfametoxazol e Trimetoprim & 144 & 47 & \\
\hline Tratou, mas não sabe o nome & 6 & 3 & \\
\hline Outros & 15 & 6 & \\
\hline \multicolumn{4}{|l|}{ Número de lesões } \\
\hline 1 & 113 & 39 & $<0,0001$ \\
\hline $2-4$ & 107 & 24 & \\
\hline$\geq 5$ & 13 & 18 & \\
\hline \multicolumn{4}{|l|}{ Tamanho da lesão } \\
\hline$<1$ & 55 & 7 & 0,0036 \\
\hline$>1$ & 178 & 74 & \\
\hline
\end{tabular}

*Excluídos os participantes com déficit cognitivo e/ou idade pré-verbal, além dos participantes que foram vistos somente uma vez. 
Em relação às complicações apresentadas ao longo do seguimento, foram analisados 295 olhos do total de 350 olhos acometidos por toxoplasmose, pois alguns participantes foram examinados somente uma vez (Tabela 8). A maioria dos olhos não apresentou complicações, totalizando 230 olhos (78\%). Ao todo, 65 olhos (22\%) tiveram complicações, sendo $14(21,5 \%)$ com complicações presentes na admissão (Tabela 8.1) e os outros 51 (78,5\%) durante o seguimento (Tabela 8.2). A análise geral dos olhos acometidos $(n=65)$ demonstrou que a membrana epirretiniana foi a complicação mais frequente, totalizando 21 olhos $(7,1 \%)$, seguida da opacidade vítrea persistente (20 olhos, 6,8\%), descolamento de retina regmatogênico e tracional (14 olhos, 4,7\%), hipertensão ocular (6 olhos, 2,0\%), buraco lamelar (2 olhos, 0,7\%), hemorragia vítrea (2 olhos, 0,7\%), glaucoma secundário (2 olhos, 0,7\%), phitisis bulbi, neovasos de coroide, edema macular, obstrução de ramo de veia central da retina e catarata. Estes últimos tiveram o acometimento de somente um olho cada (0,3\%) (Tabela 8$)$.

Tabela 8 - Complicações associadas a toxoplasmose ocular ( $\mathrm{n}=295$ olhos)

\begin{tabular}{lc}
\hline \multicolumn{1}{c}{ Complicações } & $\mathbf{N}(\%)$ \\
\hline Sem complicações & $230(78,0)$ \\
Membrana epirretiniana & $21(7,1)$ \\
Opacidade vítrea persistente & $20(6,8)$ \\
Descolamento de retina & $14(4,7)$ \\
$\quad$ Descolamento de retina regmatogênico & $7(2,4)$ \\
Descolamento de retina tracional & $7(2,4)$ \\
Hipertensão intraocular & $6(2,0)$ \\
Buraco lamelar & $2(0,7)$ \\
Hemorragia vítrea & $2(0,7)$ \\
Glaucoma secundário & $2(0,7)$ \\
Neovasos de coróide & $1(0,3)$ \\
Rasgo retiniano & $1(0,3)$ \\
Phitisis bulbi & $1(0,3)$ \\
Obstrução de ramo de veia central da retina & $1(0,3)$ \\
Catarata & $1(0,3)$ \\
\hline
\end{tabular}

$\overline{\mathrm{N}}=$ número de olhos acometidos com complicações. $\left(^{*}\right) 4$ olhos $(1,4 \%)$ apresentam mais de uma complicação 
A membrana epirretiniana, a opacidade vítrea e o descolamento de retina foram as principais causas de complicações, tanto na admissão quanto no seguimento dos participantes (Tabelas 8.1 e 8.2), sendo parte deles submetida a procedimentos cirúrgicos: cinco participantes realizaram vitrectomia posterior, dois trabeculectomia e um facoemulsificação com implante de lente intraocular.

Tabela 8.1 - Complicações associadas a toxoplasmose ocular na admissão ( $n=14$ olhos)

\begin{tabular}{lc}
\hline \multicolumn{1}{c}{ Complicações $\left(^{*}\right)$} & N (\%) \\
\hline Opacidade vítrea persistente & $6(42,9)$ \\
Membrana epirretiniana & $6(42,9)$ \\
Rasgo retiniano & $1(7,1)$ \\
Deslocamento de retina tradicional & $1(7,1)$ \\
\hline $\mathbf{N}=$ número de olhos acometidos com complicações na admissão
\end{tabular}

Tabela 8.2 - Complicações associadas a toxoplasmose ocular durante o seguimento $(n=51$ olhos*)

\begin{tabular}{lc}
\hline \multicolumn{1}{c}{ Complicações } & $\mathbf{N}(\%)$ \\
\hline Membrana epirretiniana & $15(29,4)$ \\
Opacidade vítrea persistente & $14(27,5)$ \\
Descolamento de retina & $13(25,5)$ \\
Descolamento de retina regmatogênico & $7(13,7)$ \\
Descolamento de retina tracional & $6(11,8)$ \\
Hipertensão intraocular & $6(11,7)$ \\
Hemorragia vítrea & $2(3,9)$ \\
Glaucoma secundário & $2(3,9)$ \\
Buraco lamelar & $1(1,9)$ \\
Neovasos de coroide & $1(1,9)$ \\
Phitisis bulbi & $1(1,9)$ \\
Obstrução de ramo de veia central da retina & $1(1,9)$ \\
Catarata & $1(1,9)$ \\
\hline
\end{tabular}

$\overline{\mathrm{N}}=$ número de olhos acometidos com complicações no seguimento. ( $\left.{ }^{\star}\right)$ quatro olhos $(1,4 \%)$ apresentam mais de uma complicação. 
Os fatores de risco testados para avaliar a associação com as complicações da toxoplasmose ocular foram: sexo, idade, cor da pele autodeclarada, origem, localização, tratamento, número de lesões, tamanho da lesão e presença de sorologia positiva para HIV (vírus da imunodeficiência humana). Dentre as variáveis analisadas, somente a cor da pele branca apresentou valor significativo $(p=0,0247)$, indicando que esses participantes desenvolveram mais complicações no decorrer da doença (Tabela 9). 
Tabela 9 - Fatores de risco associados à presença de complicação nos participantes com toxoplasmose ocular $(n=295)$

\begin{tabular}{|c|c|c|c|}
\hline \multirow{2}{*}{ Fatores de risco } & \multicolumn{2}{|c|}{ Complicações } & \multirow{2}{*}{$p$ - Valor } \\
\hline & Não $(n=230)$ & $\operatorname{Sim}(n=65)$ & \\
\hline \multicolumn{4}{|l|}{ Sexo } \\
\hline Feminino & 130 & 31 & 0,2068 \\
\hline Masculino & 100 & 34 & \\
\hline \multicolumn{4}{|l|}{ Idade } \\
\hline$\leq 17$ & 30 & 6 & 0,5104 \\
\hline $18-64$ & 186 & 53 & \\
\hline$\geq 65$ & 14 & 6 & \\
\hline \multicolumn{4}{|l|}{ Cor da pele autodeclarada } \\
\hline Branca & 80 & 34 & 0,0247 \\
\hline Parda & 113 & 25 & \\
\hline Negra & 35 & 5 & \\
\hline \multicolumn{4}{|l|}{ Origem } \\
\hline Primária & 38 & 16 & 0,0858 \\
\hline Recorrente Ativa & 80 & 27 & \\
\hline Recorrente Inativa & 112 & 22 & \\
\hline \multicolumn{4}{|l|}{ Localização } \\
\hline Periférica & 115 & 32 & 0,051 \\
\hline Central macular & 44 & 7 & \\
\hline Central outra & 36 & 19 & \\
\hline Central e periférica & 35 & 7 & \\
\hline \multicolumn{4}{|l|}{ Tratamento } \\
\hline Nunca tratou & 34 & 5 & 0,2246 \\
\hline Sulfadiazina e Pirimetamina & 38 & 10 & \\
\hline Sulfametoxazol e Trimetoprim & 138 & 41 & \\
\hline Tratou, mas não sabe o nome & 8 & 1 & \\
\hline Outros & 11 & 7 & \\
\hline \multicolumn{4}{|l|}{ Número de lesões } \\
\hline 1 & 114 & 33 & 0,4924 \\
\hline $2-4$ & 95 & 29 & \\
\hline$\geq 5$ & 21 & 3 & \\
\hline \multicolumn{4}{|l|}{ Tamanho da lesão } \\
\hline$<1$ de diâmetro de disco óptico & 47 & 7 & 0,0752 \\
\hline$>1$ de diâmetro de disco óptico & 183 & 58 & \\
\hline \multicolumn{4}{|l|}{ HIV } \\
\hline Positivo & 14 & 2 & 0,3441 \\
\hline Negativo & 216 & 63 & \\
\hline
\end{tabular}

*Excluídos os participantes que estiveram presentes em somente uma consulta ou lesões não cicatrizadas, demonstrando atividade da doença. 
Em relação ao tempo de acompanhamento dos participantes, $40 \%$ foram seguidos menos de seis meses e 60\% mais de seis meses, com 0,9 anos (aproximadamente 11 meses) como média de acompanhamento (média = 0.9) (Figura 4). A maior parte dos participantes (60\%) foi seguida por pelo menos seis meses, sendo que $40 \%$ foram acompanhados por pelo menos um ano e $11 \%$ pelo menos dois anos.

Figura 4 - Tempo de acompanhamento dos participantes ao longo do estudo $(n=267)$

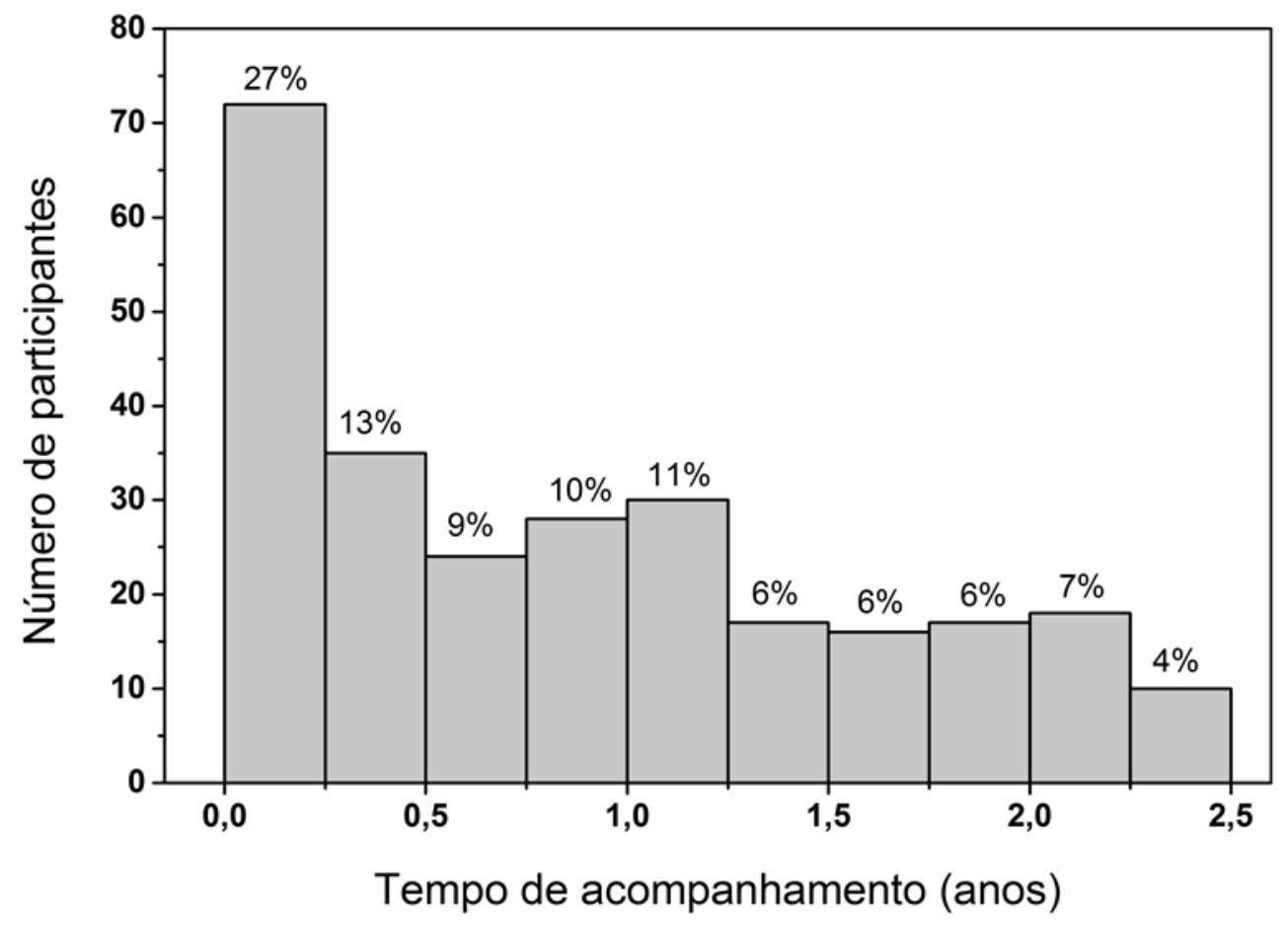

A metade das complicações dos olhos avaliados $(n=65)$ ocorreu no primeiro ano, sendo a maior parte delas durante os primeiros 0,7 anos, que seria aproximadamente 8,5 meses após o início da doença ocular (Figura 5) (média = 0.67). 
Figura 5 - Relação de complicações oculares com o tempo de acompanhamento ( $\mathrm{n}=65$ olhos*). *Excluídos os indivíduos atendidos apenas na admissão e os que não tiveram complicações

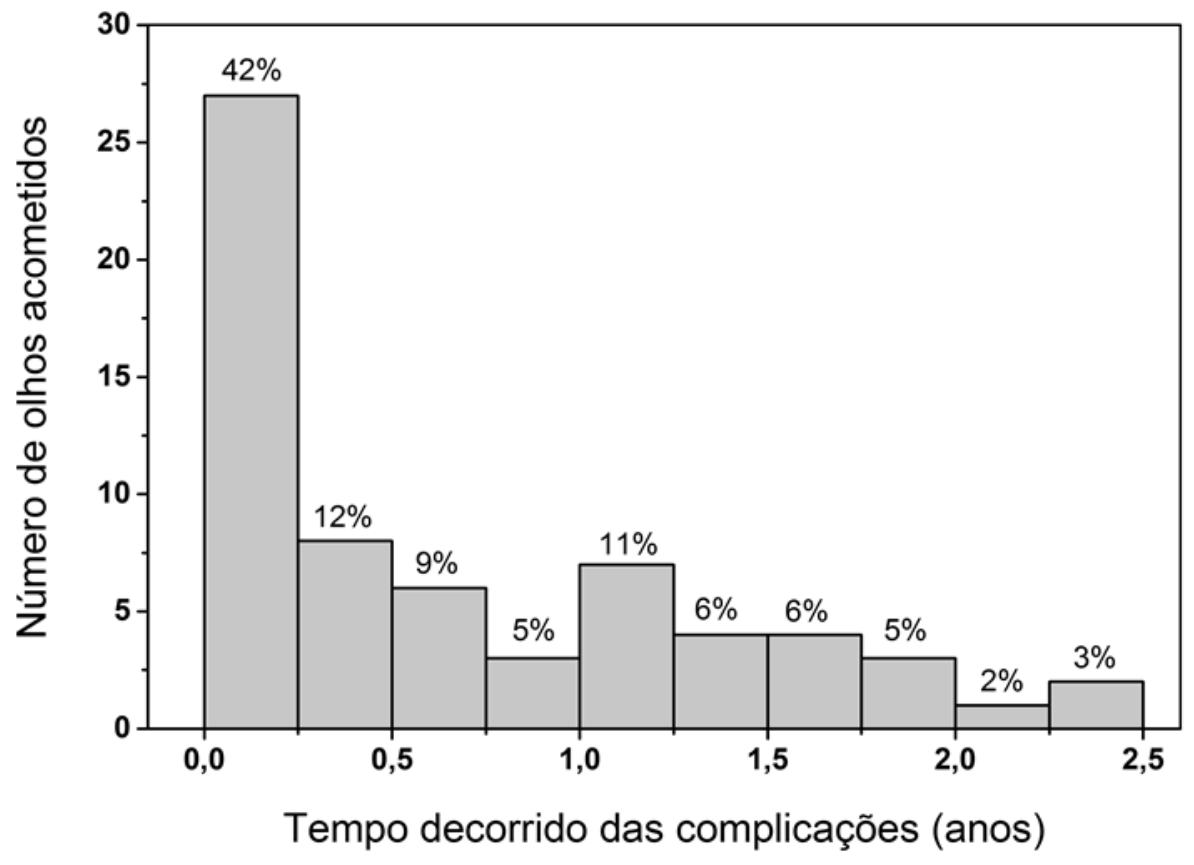

A correlação do tempo de acompanhamento com o número de complicações está descrita na Figura 6. Observou-se que a chance de uma pessoa apresentar complicações no período de um ano é de cerca de $41 \%$ (média $=0,41$ ), sendo que 90\% deles apresentaram até uma complicação por olho ao ano. 
Figura 6 - Taxa de incidência de complicações oculares ao longo do acompanhamento

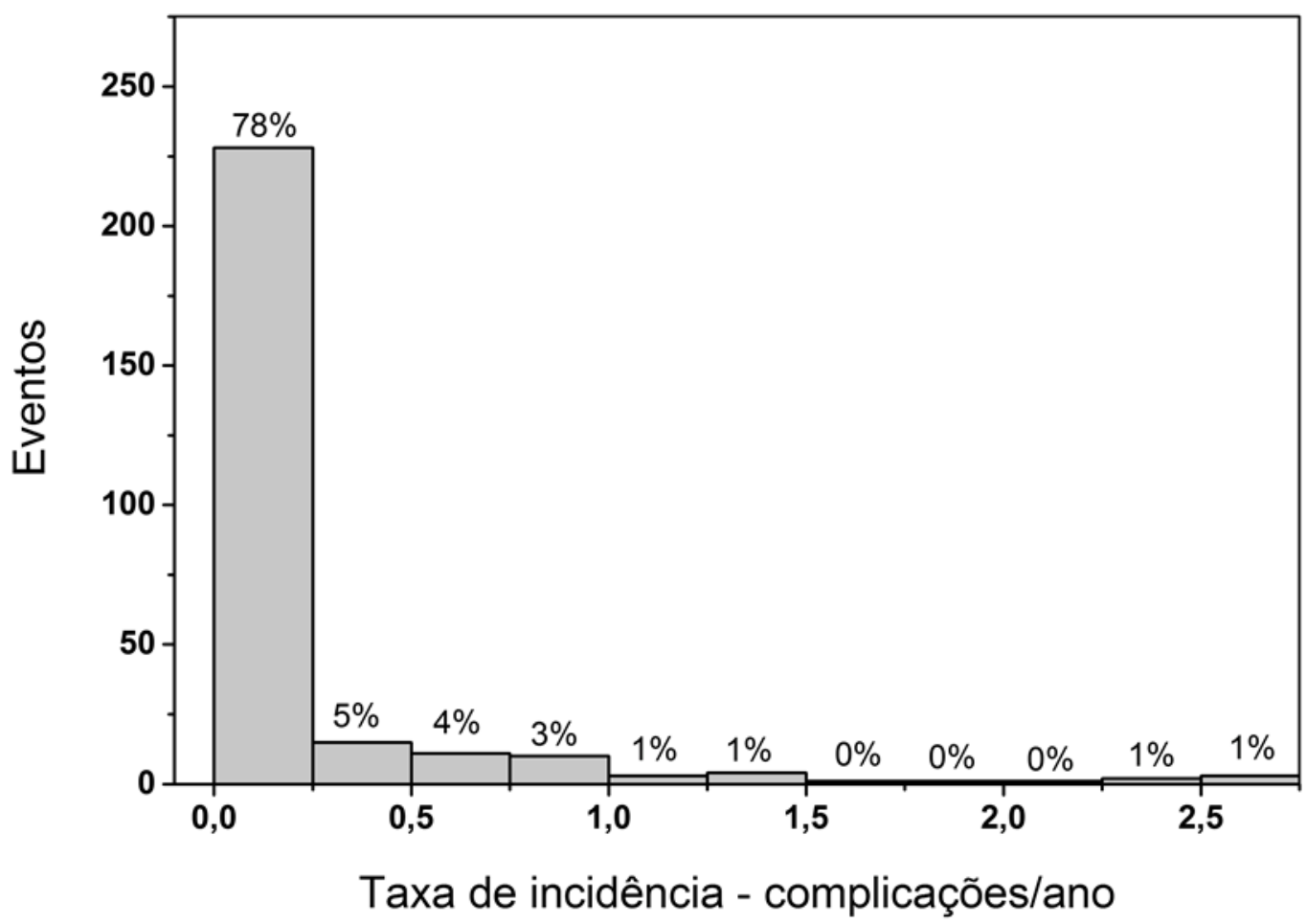

As reativações aconteceram em 26 olhos (24 participantes; dois com acometimento bilateral), sendo que em 15 deles essas reativações ocorreram até o primeiro ano de seguimento (média $=1.06$ ) (Figura 7). 
Figura 7 - Tempo decorrido para reativação por olho $(\mathrm{n}=26)$

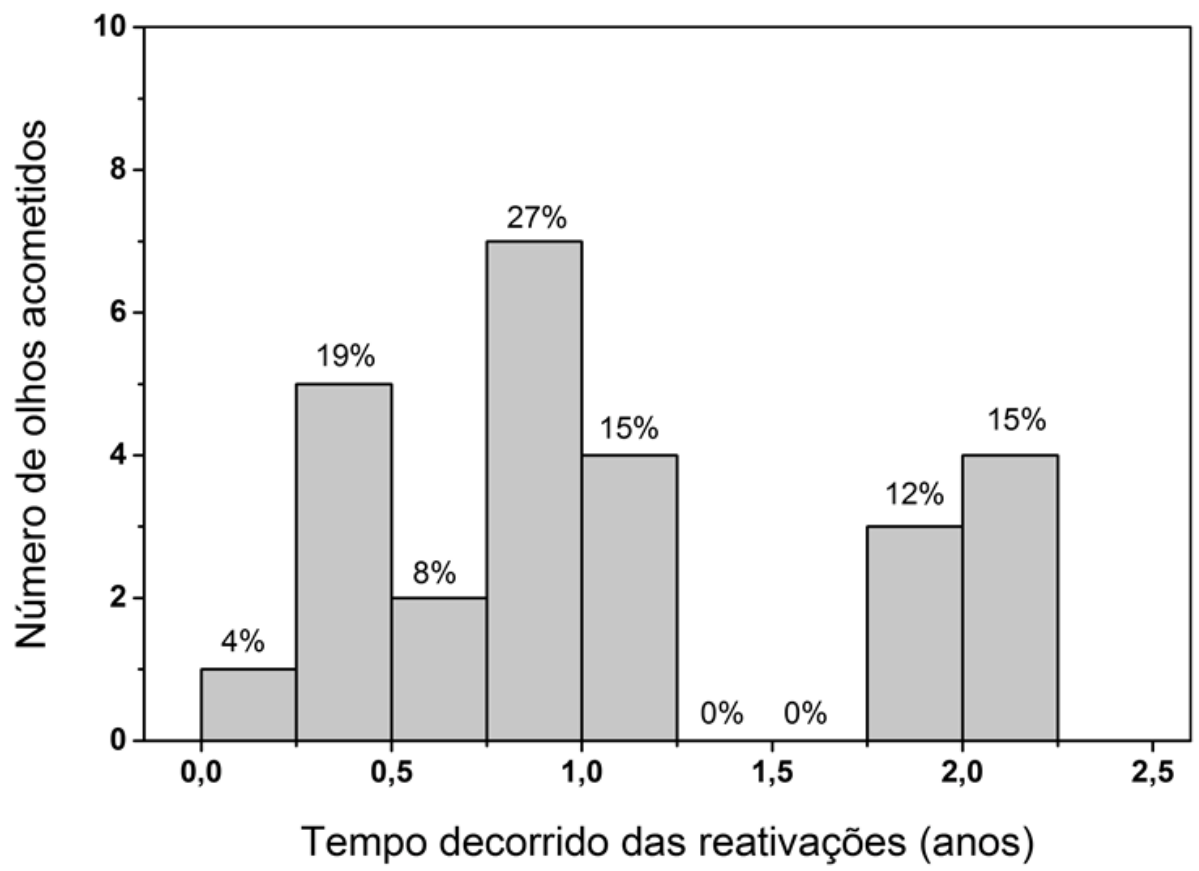

8).

As reativações apresentaram média por pessoa de 0,13 reativações/ano (Figura

Figura 8 - Taxa de incidência de reativação associada com o tempo de acompanhamento

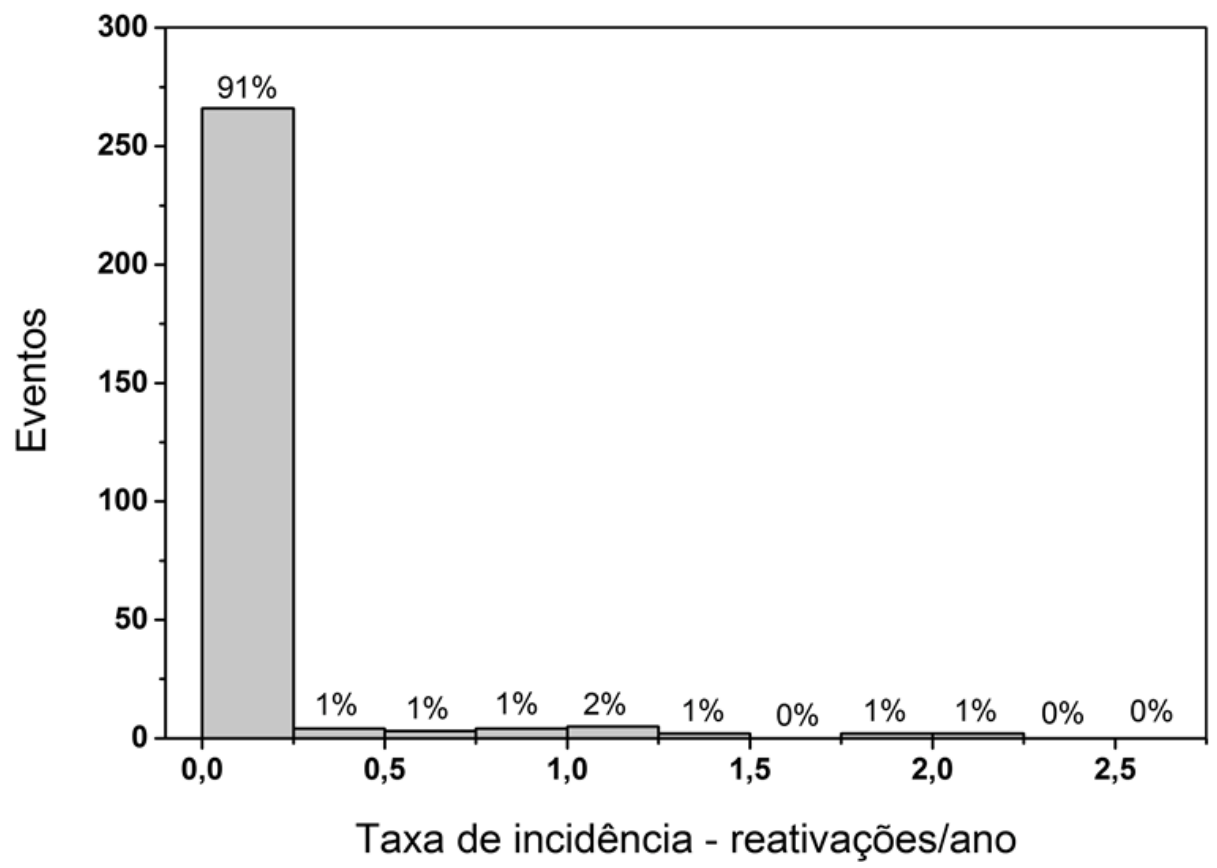


A profilaxia, quando necessária, foi instituída nos participantes $(n=71)$ com casos recorrentes de múltiplas lesões ativas e/ou próximas da região macular. Vinte e quatro participantes tiveram recidiva da toxoplasmose ocular, sendo que dez deles estavam fazendo o uso de profilaxia. Neste estudo, não foram encontradas diferenças estatísticas significativas entre o uso de profilaxia e a menor taxa de recidiva $(p=0,2814)$ (Tabela 10$)$.

Tabela 10 - Correlação entre profilaxia versus recidiva

\begin{tabular}{cccc} 
& \multicolumn{3}{c}{ Reativação } \\
\cline { 2 - 3 } Profilaxia & Não & Sim & Total \\
\hline Não & 137 & 14 & 151 \\
Sim & 61 & 10 & 71 \\
\hline Total & 198 & 24 & $222^{*}$ \\
\hline
\end{tabular}

Teste qui-quadrado; $p=0,2814$. *Excluídos os participantes que foram examinados somente uma vez, ou que ainda apresentavam lesão ativa. 
6. Discussão 
No presente estudo foram avaliados 267 participantes ( $\mathrm{n}=350$ olhos), apresentando complicações em 65 olhos (22\%), recidiva da doença em 25 (8,8\%) e cegueira bilateral em sete (2,2\%), tendo como fatores de risco as lesões centrais, múltiplas com tamanho maior de um diâmetro de disco óptico. A comparação de alguns dos achados deste estudo com outros estudos semelhantes está presente na Tabela 11. A média de idade encontrada foi de 36,36 anos, com distribuição homogênea em relação ao sexo. A maior parte dos estudos indicou maior acomentimento nas $2^{\mathrm{a}}$ e $3^{\mathrm{a}}$ décadas de vida, sem predileção entre os sexos, como evidenciado na Tabela 11. ${ }^{18,34-36}$

A origem da infecção foi caracterizada como indeterminada em 86,1\% dos participantes, pela dificuldade em identificar o momento exato da infecção, já que a doença ocular pode aparecer anos após a infecção sistêmica de T. gondii ${ }^{37}$. Um estudo anterior, realizado em Erechim-RS, revelou que 8,3\% de indivíduos sem lesões retinianas prévias, mas com soropositividade para toxoplasmose, desenvolveram a doença ocular após sete anos de acompanhamento. ${ }^{38}$ Devido a isso, imaginou-se que a maioria tenha sido adquirida no pós-natal. Os casos de toxoplasmose congênita se resumiram a $9 \%$, quadro idêntico ao estudo realizado por Bosch-Driessen et al. ${ }^{32}$

A sorologia para a toxoplasmose com anticorpos lgM positivos (indicando infecção aguda) foi detectada em 22 (8,2\%) dos participantes seguidos. A baixa porcentagem, também observada em outro estudo brasileiro $(9,1 \%)^{35}$, leva a concluir que a maioria das lesões oculares ativas se desenvolve meses ou anos após a infecção.

A maioria das lesões se apresentou com características típicas, como na maior parte das pesquisas realizadas, com número bem restrito de casos atípicos $(3,4 \%)$, nos quais se incluiram participantes com toxoplasmose ativa bilateral e/ou lesões ativas extensas/múltiplas. ${ }^{18}$

Dos participantes incluídos no estudo, 52,8\% apresentavam toxoplasmose ocular ativa $(52,8 \%)$, sendo $19,5 \%$ primária, 33,3\% recorrente ativa e 47,2\% recorrente inativa. Outro estudo brasileiro demonstrou taxas mais elevadas: $22,6 \%$ dos participantes com toxoplasmose primária e 77,4\% com lesões recorrentes ativas. $^{35}$ 
As características clínicas dos participantes com cicatriz de retinocoroidite quanto à lateralidade das lesões foram de predominância unilateral, compatíveis com estudos anteriores realizados, tanto no Brasil quanto nos Estados Unidos, e em alguns países asiáticos (Tabela 11) ${ }^{18,32,35,36,39-41}$ Importante observar que 48,9\% dos participantes apresentaram lesões centrais, isoladas e/ou associadas a lesões periféricas, porém com frequência inferior aos achados do estudo de Aleixo et al. ${ }^{35}$, que apresentou taxa de 74,8\%. A localização dessas lesões representa risco potencial de levar à baixa da AV do olho acometido, já que esta região possui maior densidade de fotorreceptores. As lesões bilaterais foram encontradas em $31 \%$ dos casos, observado fato semelhante em outra série de casos, que citam acometimento de $22-44 \%$ dos indivíduos. ${ }^{32,37,42,43}$

Os olhos cegos (AV <20/400) encontrados estavam presentes em aproximadamente 25,8\%, semelhante ao observado em outros estudos brasileiros $^{7,32,35}$, porém superior aos achados do estudo de Bosch-Driessen et al. $(19 \%) .{ }^{32}$ Foi detectada cegueira bilateral em sete participantes $(2,2 \%)$, frequência ligeiramente maior comparada ao estudo de Bosch-Driessen et al. ${ }^{32}$ (1\%). A localização central da cicatriz retiniana, provocada pela toxoplasmose, juntamente com múltiplas lesões de tamanho maior que um diâmetro de disco foram fatores de risco para a baixa da AV neste estudo nas lesões cicatrizadas. Não foram contabilizados, neste cálculo, os pacientes com lesões ativas, pois a AV pode melhorar após a cicatrização.

Bosch-Driessen et al. $^{44}$ avaliaram no mesmo estudo, as complicações oculares associadas à toxoplasmose ocular, obtendo $6 \%$ de frequência de descolamento de retina. No presente estudo observou-se este evento em 5,4\% dos participantes (4,7\% dos olhos), considerado bem menor em relação a outro estudo realizado nos Estados Unidos, no qual 11,4\% dos participantes tiveram esta complicação. ${ }^{41}$ Apesar da porcentagem maior, tanto o estudo holandês quanto o americano, mostraram média de acompanhamento dos participantes superior à do presente estudo (média de cinco meses), com 5,8 anos e 22,5 meses de média de acompanhamento, respectivamente. ${ }^{44,45} \mathrm{O}$ desenvolvimento de membrana epirretiniana em $9,4 \%$ dos participantes $(7,1 \%$ dos olhos) foi superior em relação ao estudo americano (1,9\% participantes com lesões inativas) e um estudo 
multicêntrico, que indicou $3,1 \%$ dos participantes. ${ }^{18,36}$ Embora tenha sido a complicação mais frequente neste estudo, outro estudo brasileiro demonstrou que a mesma complicação estava presente em $27,1 \%$ dos olhos. ${ }^{35} \mathrm{O}$ advento da tomografia de coerência óptica possibilitou que a membrana epirretiniana fosse mais fácilmente detectada; e com isso, estudos antigos podem hipoestimar esta complicação. O desenvolvimento de opacidade vítrea persistente de 9,0\% dos participantes (6,8\% dos olhos) acometidos, também foi inferior ao estudo americano, o qual apresentou $21 \%$ de acometimento ocular ${ }^{32}$. Importante salientar que deve ser feito um exame cuidadoso da retina em pacientes com toxoplasmose ocular, especialmente nos indivíduos com fatores de risco associados, como miopia e inflamações intraoculares muito graves.

A maior parte dos participantes que receberam tratamento prévio estava em uso de terapia combinada de antibiótico (Sulfametoxazol com Trimetoprim) e corticoesteroide, independente da localização da lesão, embora um estudo realizado com oftalmologistas brasileiros revelou que os mesmos optam pelo esquema clássico (Sulfadiazina, Pirimetamina e Ácido folínico) quando a lesão se localiza na região central (70.4\%), e nas infecções adquiridas $(70.4 \%)$ e atípicas $(74.1 \%) .{ }^{46}$ Embora a terapia tripla clássica de Pirimetamina, Sulfadiazina e corticosteroide seja uma escolha eficaz, os regimes terapêuticos alternativos, incluindo o tratamento com Sulfametoxazol e Trimetoprim, demonstraram ser eficazes contra a toxoplasmose ocular. $^{47,48}$ A utilização dessa combinação é agora a preferida por muitos devido à melhor adesão do paciente, sendo segura para o tratamento da toxoplasmose ocular. $^{47,48}$ Devido a isto, alguns casos atípicos do presente estudo receberam tratamento com Sulfametoxazol e Trimetoprim. Atualmente, não há fármaco que elimine o toxoplasma do organismo, pois os mesmos só agem na forma replicante (taquizoita) do hospedeiro, além de não haver consenso sobre o melhor regime de tratamento. $^{49}$

A taxa de recidiva deste estudo foi bem menor em relação a outro estudo brasileiro, pois enquanto o presente estudo demonstrou recorrência da toxoplasmose em $10,8 \%(n=24)$ dos participantes no seguimento, com relação de 0,13 episódios/ano, o outro, em contrapartida, apresentou-se com 45,2\% durante todo o estudo, $32,7 \%$ no primeiro ano; $32,7 \%$ no segundo ano e $34,6 \%$ nos anos 
seguintes. ${ }^{35}$ Outros estudos também evidenciaram taxas maiores, porém com tempo de seguimento superior; como, por exemplo, no estudo do Rothova ${ }^{50}$, em que a recidiva aproximava-se de $50 \%$ durante o período de três anos, e no estudo de Bosch-Driessen et al. $^{51}$, que evidenciou $57 \%$ de recidivas o período médio de 4,6 anos, sendo $29 \%$ no primeiro ano e $57 \%$ no segundo ano, não sendo identificados os fatores de risco para que ocorressem as recidivas. Tugal-Tutkun et al. ${ }^{39}$ relataram que quanto maior o tempo de acompanhamento, maior a porcentagem de recidivas, porém não devendo ser interpretado como risco aumentado para recorrência da doença. Os autores observaram $23,8 \%$ de recidivas ao longo do seguimento, sendo que $65 \%$ ocorreram nos primeiros dois anos após o primeiro evento. London et al, ${ }^{18}$ encontraram 8,8\% no primeiro ano após acompanhamento no período médio de 8,2 meses, demonstrando ser o mais próximo do presente estudo nesse quesito (Tabela 11).

A profilaxia instituída para casos de recidiva, ou participantes com lesões múltiplas, ou próximas da região macular e/ou participantes com olho único, foi realizada com Sulfametaxazol 800 mg e Trimetoprim 160 mg, um comprimido em dias alternados, três vezes na semana. Posteriormente, foi constatado que dos 71 participantes que receberam o esquema terapêutico, 10 apresentaram recidiva, com valor de $p=0,2814$, indicando não haver diferença entre os que fizeram uso da profilaxia e os que não utilizaram a mesma. Em contrapartida, o estudo do Felix et al. ${ }^{19}$, com a mesma medicação, mostrou redução de $100 \%$ da recorrência ao longo de um ano, e o de Silveira et al. ${ }^{52}$ apresentou recorrências de somente $6,6 \%$ dos participantes tratados em comparação com $23,8 \%$ de recidiva no grupo controle. Apesar dos indícios de que a profilaxia diminua as chances de ocorrência de um novo evento, este estudo não demonstrou benefícios, talvez pelo número reduzido da amostra, curto tempo de acompanhamento, ou omissão do uso da medicação pelos participantes avaliados. Além disso, os participantes dos estudos citados eram todos sorteados para receber a profilaxia no grupo selecionado para tal fim, enquanto que no presente estudo só era prescrita para aqueles com risco aumentado de recidivas.

A maior parte dos estudos realizados até hoje sobre o tema é retrospectiva, foram desenvolvidos em diferentes centros, tendo as suas análises baseadas em 
informações colhidas por terceiros em banco de dados. Este estudo, por ser prospectivo, apresentou como ponto positivo a elaboração de um formulário para a padronização na coleta de dados, realizada sempre pelas mesmas pessoas, além de ter um único centro para ser avaliado, resultando em menor viés. Somado a isto, o número de amostras deste estudo, comparado ao de outras pesquisas realizadas anteriormente, demonstra significância, somado à boa documentação de imagens (retinografia colorida e tomografia de coerência óptica).

As limitações encontradas no presente estudo foram relacionadas à perda de seguimento de alguns pacientes e, portanto, a taxa de recorrência e de complicações encontradas pode não ser fidedigna. Vale ressaltar que alguns participantes foram encaminhados da Unidade de Emergência do HCFMRP-USP, já recebendo tratamento para toxoplasmose, implicando na avaliação do paciente "virgem de tratamento", além de não ser possível precisar qual o tempo correto da cicatrização das lesões, já que houve certa demora entre o encaminhamento da Unidade de Emergência e o recrutamento para a pesquisa. Outros fatores implicados neste quesito foram: tempo curto de duração do estudo, já que o mesmo teria que ser adequado ao tempo da pesquisa proposta; estudo não populacional, que algumas alterações, como complicações e reativações, por exemplo, não correspondam ao universo total de pessoas com toxoplasmose ocular. Espera-se, por exemplo, que pessoas com lesões pequenas e periféricas nem procurem 0 serviço. Nesse sentido, a gravidade dos casos desta amostra pode ser maior do que a encontrada em estudos populacionais.

Alguns pontos necessitam de mais estudos para elucidar a correlação da profilaxia com a diminuição da recorrência em alguns pacientes, já que neste estudo, os poucos dados coletados, em curto espaço de tempo, não permitiram a analogia. 
Tabela 11 - Comparação de estudos clínicos sobre toxoplasmose ocular

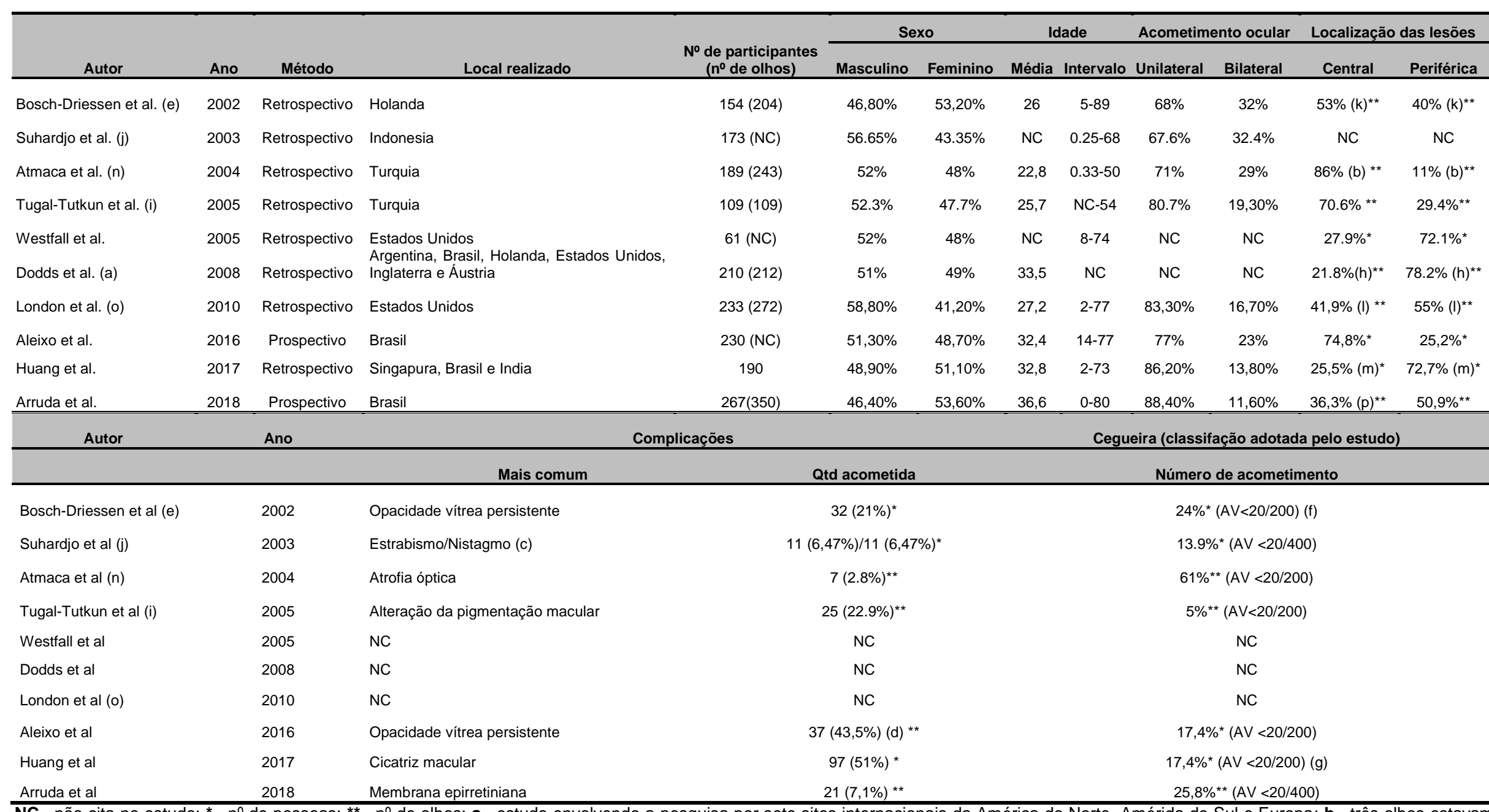

NC= não cita no estudo; ${ }^{*}=n^{0}$ de pessoas; ${ }^{* *}=n^{0}$ de olhos; $\mathbf{a}=$ estudo envolvendo a pesquisa por sete sites internacionais da América do Norte, Amérida do Sul e Europa; $\mathbf{b}=$ três olhos estavam na macula e periferia. Os outros seis olhos tinham somente vitreite e papilite; $\mathbf{c}=0$ os participantes, em sua maioria $(\mathrm{N}=170)$, tinham toxoplasmose congênita; $\mathbf{d}=$ dos 230 participantes, $73(31,7 \%)$ tiveram complicaçoes, sendo mais comum a opacidade vitrea persistente, seguida da membrana epirretiniana; $\mathbf{e}=$ estudo que engloba somente toxoplasmose ativa, $\mathbf{f}=$ em dois pacientes dos 154 , foram considerados com cegueira legal bilateral ( $1 \%$ dos participantes); $\mathbf{g =}$ Dos 190 pacientes, 155 tiveram o registro da acuidade visual final; $\mathbf{h}=\mathrm{N}=206$ olhos, os outros olhos nao tiveram
anotação da localização; $\mathbf{i}=$ estudo que engloba somente toxoplasmose ativa; $\mathbf{j}=$ Estudo com 170 participantes com toxoplasmose congenita e somente três participantes com toxoplasmose adquirida; $\mathbf{k}=$ Número total de 204 OLHOS, porém 15 olhos (7\%) tinham acometimento central + periferico. Ele não classifica por participante essa classificação referente à localização. 
7. Conclusões 
Após análise dos resultados, concluiu-se que:

- A toxoplasmose ocular atingiu ambos os sexos, aproximadamente na $4^{\mathrm{a}}$ década de vida, apresentando, em sua maioria, única lesão monocular, maior que um tamanho de disco óptico, localização periférica, de origem indeterminada e recorrente inativa.

- As complicações: membrana epirretiniana, descolamento de retina e opacidade vítrea persistente foram as mais observadas, aparecendo, em sua maioria, no primeiro ano de doença ocular, com média de 0,41 complicações/ano.

- Altas taxas de déficit visual foram encontradas, associado com múltiplas lesões, localização central (macular) e tamanho da lesão (maior que um diâmetro de disco óptico).

- As recidivas obtiveram média de 0,13 reativações/ano por pessoa, não apresentando benefícios, neste estudo, com o uso de profilaxia. 


\section{Referências Bibliográficas ${ }^{1}$}

${ }^{1}$ Elaboradas de acordo com as Diretrizes para Elaboração de Dissertações e Teses da USP: Documento Eletrônico e Impresso - Parte IV (Vancouver) 3 $3^{\mathrm{a}}$ Ed. Revisada, Ampliada e Modificada. São Paulo: SIBi/USP, 2016. 
1 Montoya JG, Liesenfeld O. Toxoplasmosis. Lancet. 2004;363(9425):1965-76.

2 Black MW, Boothroyd JC. Lytic cycle of Toxoplasma gondii. Microbiol Mol Biol Rev. 2000;64(3):607-23.

3 Montoya JG, Remington JS. Management of Toxoplasma gondii infection during pregnancy. Clin Infect Dis. 2008;47(4):554-66.

4 Derouin F, Pelloux H. Prevention of toxoplasmosis in transplant patients. Clin Microbiol Infect. 2008;14(12):1089-101.

5 Holland GN. Ocular toxoplasmosis: a global reassessment. Part II: disease manifestations and management. Am J Ophthalmol. 2004;137(1):1-17.

6 Orefice $\mathrm{F}$ et al. Toxoplasmose ocular adquirida: toxoplasmose ocular pós-natal. Rev Bras Oftalmol. 2010;69 (3): 184-207.

7 Butler $\mathrm{NJ}$ et al. Ocular toxoplasmosis II: clinical features,pathology and management. Clin Experiment Ophthalmol. 2013;41(1):95-108.

8 Glasner PD et al. An unusually high prevalence of ocular toxoplasmosis in southern Brazil. Am J Ophthalmol. 1992;114(2):136-44.

9 Silveira $\mathrm{C}$ et al. A follow-up study of Toxoplasma gondii infection in southern Brazil. Am J Ophthalmol. 2001;131(3):351-4.

10 Silveira $\mathrm{C}$ et al. Acquired toxoplasmic infection as the cause of toxoplasmic retinochoroiditis in families. Am J Ophthalmol. 1988;106(3):362-4.

11 Sibley LD et al. Genetic approaches to studying virulence and pathogenesis in Toxoplasma gondii. Philos Trans R Soc Lond B Biol Sci. 2002;357(1417):81-8.

12 12.Israelski DM, Remington JS. Toxoplasmosis in the non-AIDS immunocompromised host. Curr Clin Top Infect Dis. 1993;13:322-56.

13 Holland GN et al. Toxoplasmosis In: Pepose JS, Holland GS, Wilhelmus KR (eds). Ocular infection and immunity. St. Louis: Mosby. 1996; p. 1183-223.

14 Dubey JP et al. Experimental toxoplasmosis in rats induced orally with eleven strains of toxoplasma gondii of seven genotypes: tissue tropism, tissue cyst size, neural lesions, tissue cyst rupture without reactivation, and ocular lesions. PLoS One. 2016;11(5):e0156255.

15 Nicholson $\mathrm{DH}$, Wolchok EB. Ocular toxoplasmosis in an adult receiving long-term corticosteroid therapy. Arch Ophthalmol. 1976;94(2):248-54.

16 Holland GN et al. Ocular toxoplasmosis in patients with the acquired immunodeficiency syndrome. Am J Ophthalmol. 1988;106(6):653-67. 
17 Montoya JG, Kovacs JA, Remington JS. Toxoplasma gondii. In: Mandell GL, Bennett JE, Dolin R (eds). Principles and practice of infectious diseases. 6th ed. Philadelphia: Churchill Livingstone. 2010; p. 3495-510.

18 London NJ, Rathinam SR, Cunningham ET Jr. The epidemiology of uveitis in developing countries. Int Ophthalmol Clin. 2010;50(2):1-17.

19 Felix JPF et al. Trimethoprim-Sulfamethoxazole Versus Placebo to Reduce the Risk of Recurrences of Toxoplasma Gondii Retinochoroiditis: Randomized Controlled Clinical Trial. Am J Ophthalmol. 2014;157(4):762-766.e1.

20 Furtado JM et al. Ocular toxoplasmosis I: parasitology, epidemiology and public health. Clin Experiment Ophthalmol. 2013;41(1):82-94.

21 Abu EK et al. Epidemiology of ocular toxoplasmosis in three community surveys in the Central Region of Ghana, West Africa. Ophthalmic Epidemiol. 2016;23(1):14-9.

22 Jones JL, Parise ME, Fiore AE. Neglected Parasitic Infections in the United States: Toxoplasmosis. The Am J Trop Med Hyg. 2014;90(5):794-9.

23 Vasconcelos-Santos DV et al. Congenital toxoplasmosis in southeastern Brazil: results of early ophthalmologic examination of a large cohort of neonates. Ophthalmology. 2009;116(11):2199-205 e2191.

24 Gilbert RE et al. Ocular sequelae of congenital toxoplasmosis in Brazil compared with Europe. PLoS Negl Trop Dis. 2008;2(8):e277.

25 Furtado JM et al. Causes of blindness and visual impairment in Latin America. Surv Ophthalmol. 2012;57(2):149-77.

26 Haddad MA et al. Causes of visual impairment in children: a study of 3,210 cases. J Pediatr Ophthalmol Strabismus. 2007;44(4):232-240.

27 Fernandes GC et al. Seroepidemiology of Toxoplasma infection in a metropolitan region of Brazil. Epidemiol Infect. 2009;137(12):1809-15.

28 Guimarães $A C$ et al. Regional variation in toxoplasmosis seronegativity in the São Paulo metropolitan region. Rev Inst Med Trop Sao Paulo. 1993;35(6):47983.

29 Khan A et al. Genetic divergence of Toxoplasma gondii strains associated with ocular toxoplasmosis, Brazil. Emerg Infect Dis. 2006;12(6):942-9.

30 Dubey JP, Frenkel JK. Feline toxoplasmosis from acutely infected mice and the development of Toxoplasma cysts. J Protozool. 1976;23(4):537-46. 31.32. 
31 Orefice $\mathrm{F}$ et al. Acquired Ocular Toxoplasmosis in Brazilian Patients. Invest. Ophthalmol. Vis. Sci. 2009;50(13):6040.

32 Bosch-Driessen LE et al. Ocular toxoplasmosis: clinical features and prognosis of 154 patients. Ophthalmology. 2002;109(5):869-78.

33 Silva LM et al. Visual impairment from uveitis in a reference hospital of Southeast Brazil: a retrospective review over a twenty years period. Arq Bras Oftalmol. 2013;76(6):366-9.

34 Dodds et al. Intraocular Inflammation Associated with Ocular Toxoplasmosis: Relationships at Initial Examination. Am J Ophthalmol. 2008 Dec;146(6):85665.e2.

35 Aleixo ALQC et al. Toxoplasmic retinochoroiditis: Clinical characteristics and visual outcome in a prospective study. PLoS Negl Trop Dis. 2016;10(5):e0004685.

36 Hogan MJ, Kimura SJ, O'Connor GR. Ocular toxoplasmosis. Arch Ophthalmol. 1964;72:592-600.

37 Arantes TE et al. Ocular involvement following postnatally acquired toxoplasma gondii infection in Southern Brazil: A 28-Year Experience. Am J Ophthalmol. 2015;159(6):1002-1012.e2.

38 Silveira, C. Toxoplasmose: levantamento bibliográfico de 1997 a 2000 . Arq. Bras. Oftalmol. 2001;64(3):263-70.

39 Tugal-Tutkun I et al. Active ocular toxoplasmosis in Turkish patients: a report on 109 cases. Int Ophthalmol. 2005;26(6):221-8.

40 Suhardjo, Utomo PT, Agni AN. Clinical manifestations of ocular toxoplasmosis in Yogyakarta, Indonesia: a clinical review of 173 cases. Southeast Asian J Trop Med Public Health. 2003;34(2):291-7.

41 Atmaca LS, Simsek T, Batioglu F. Clinical features and prognosis in ocular toxoplasmosis. Jpn J Ophthalmol. 2004;48(4):386-91.

42 Friedmann CT, Knox DL. Variations in recurrent active toxoplasmic retinochoroiditis. Arch Ophthalmol. 1969;81(4):481-93.

43 Rothova A. Ocular involvement in toxoplasmosis. $\mathrm{Br} \mathrm{J}$ Ophthalmol. 1993;77(6):371-7.

44 Bosch-Driessen $\mathrm{LH}$ et al. Retinal detachment in ocular toxoplasmosis. Ophthalmology. 2000;107(1):36-40. 
45 Faridi $A$ et al. Retinal detachment associated with ocular toxoplasmosis. Retina. 2015;35(2):358-63.

46 Morais FB, Arantes TE, Muccioli C. Current practices in ocular toxoplasmosis: A survey of Brazilian Uveitis Specialists. Ocul Immunol Inflamm. 2016:1-7.

47 Opremcak EM, Scales DK, Sharpe MR. Trimethoprim-sulfamethoxazole therapy for ocular toxoplasmosis. Ophthalmology. 1992;99(6):920-5.

48 Ozgonul C, Besirli CG. Recent developments in the diagnosis and treatment of ocular toxoplasmosis. Ophthalmic Res. 2017;57(1):1-12.

49 Stanford MR et al. Antibiotics for toxoplasmic retinochoroiditis: an evidencebased systematic review. Ophthalmology. 2003;110(5):926-31.

50 Rothova A. Ocular involvement in toxoplasmosis. $\mathrm{Br} \mathrm{J}$ Ophthalmol. 1993;77(6):371-7.

51 Bosch-Driessen $\mathrm{EH}$ et al. Recurrent ocular disease in postnatally acquired toxoplasmosis. Am J Ophthalmol. 1999;128(4):421-5.

52 Silveira $\mathrm{C}$ et al. The effect of long-term intermittent trimethoprim/sulfamethoxazole treatment on recurrences of toxoplasmic retinochoroiditis. Am J Ophthalmol. 2002;134(1):41-6. 
9. Anexos 


\section{ANEXO A}

\section{COMPROVANTE DE APROVAÇÃO DO COMITÊ DE ÉTICA}

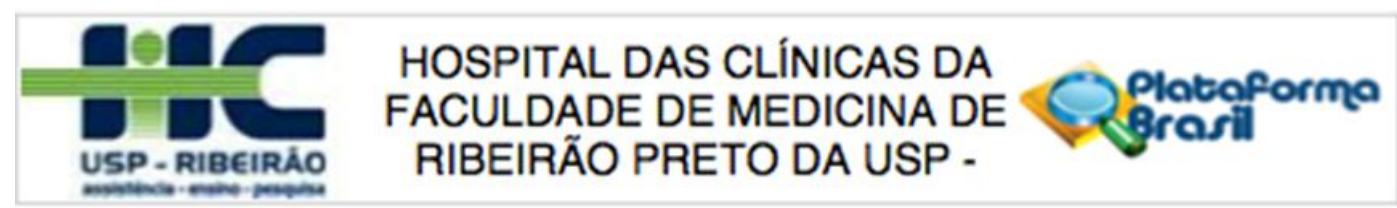

Continusglo do Parecer: 1.153720

de sinais de atividade da doença, sorologia anti-toxoplasma (lgG e lgM), forma (adquirida ou congénita), tratamento instituido e complicapōes clinicas.

\section{Objetivo da Pesquisa:}

Analisar as manifestações clinicas da toxoplasmose ocular em relação a número de lesões, recorrẻncia, lateralidade, acuidade visual e complicaçōes clinicas; Comparar as variáveis mencionadas no item acima, de acordo com sexo, etnia, forma de contágio e diferentes padrōes de sorologias encontradas.

\section{Avaliação dos Riscos e Beneficios:}

Riscos: Quanto aos riscos, nāo haverá nenhum dano potencial direto à saủde dos sujeitos pela simples inclusāo à pesquisa, pois o estudo trata-se de uma observaçẫo dos achados clinicos em pacientes seguidos no Ambulatório de Uveites do HCFMRP.USP. Os exames clínicos serão feitos de acordo com a necessidade individual de cada paciente e os tratamentos instituidos serão realizados de acordo com o tratamento proposto por conceituados artigos científicos na área. Deve-se considerar potencias riscos envolvendo a violação da privacidade dos sujeitos de pesquisa. Para evita-los serāo feitos todos os esforços para manter a confidencialidade (sigilo) das informaçōes e 0 anonimato dos participantes. As publicaçōes deste estudo não usarão nomes ou qualquer outro dado que possa identificar os participantes.

Beneficios: $O$ presente estudo não terá beneficio direto a nenhum dos sujeitos de pesquisa avaliados. No entanto os resultados servirão para a melhor compreensấo sobre a doença, especialmente em relação a aspectos como prognóstico desta condição clinica, e resposta ao tratamento. Tais medidas poderão beneficiar outros individuos no futuro.

\section{Comentários e Consideraçōes sobre a Pesquisa:}

Casuistica $O$ estudo se baseará na inclusão de pacientes do HCFMRP.USP com o diagnóstico de toxoplasmose ocular, e a verificação dos dados laboratoriais da sorologia anti-toxoplasma, presente no Sistema Athos (Servidor HCFMRP.USP). 4.2. Desenho do Estudo Estudo coorte prospectivo. 4.3. Local de realização do estudo $O$ estudo em questão será realizado no ambulatório do setor de Uveites no HCFMRP. USP. 4.4. Participantes e critérios de inclusão Todos os pacientes de ambos os sexos atendidos no durante os anos de 2015 e 2016 com diagnóstico de toxoplasmose ocular (aguda, reativada ou cicatrizada), serão selecionados e convidados a participar do estudo. Para o 


\section{HOSPITAL DAS CLÍNICAS DA $\square \square$ FACULDADE DE MEDICINA DE RIBEIRÃO PRETO DA USP .}

Continusplo do Parecer: 1.153720

presente estudo, o diagnóstico de toxoplasmose ocular será feito com base na visualização de lesōes retinianas tipicas descritas na literatura,5 na ausência de outras possiveis causas, aliada à presença de sorologia positiva anti-toxoplasma (lgG e/ou lgM). (Anexo 1). 4.5. Variáveis estudadas As variáveis estudadas são: sexo, idade, etnia, forma de aquisiçāo da toxoplasmose, tratamento realizado, lateralidade (olho direito, esquerdo ou ambos), medida da acuidade visual, sorologia lgG e lgM, número, tamanho e localização das lesōes retinianas causadas pelo T. gondii. O quadro será definido como toxoplasmose ocular primária quando for verificada na fundoscopia lesão retiniana focal branca ativa sem cicatrizes retinianas em qualquer olho. $O$ quadro será classificado como recorrente quando houver a presença de cicatrizes retinianas em qualquer olho com lesão retiniana focal branca ativa (=ativa) ou sem lesão retiniana focal branca ativa (=inativa). em relaçẫo à localização das lesões, a doença será classificada como central (quando as lesōes estiverem entre as arcadas vasculares temporais) e periféricas (fora das arcadas vasculares temporais). 19 4.6. Fonte de dados e meios de medir as variáveis Os dados serão obtidos a partir da anamnese e exame fisico dos participantes do estudo (lâmpada de fenda e biomicroscopia), e serão anotados em um formulário de coleta de dados (Anexo 1). O número de lesōes será verificado na fundoscopia, e o tamanho das mesmas será estimado em diâmetro de discos ópticos. As complicações encontradas serão anotadas a partir da visualização direta no exame oftalmológico. 4.7. Potenciais vieses Um potencial viés é possivelmente não incluirmos todos os elegiveis para o estudo. Para minimizar este risco, os pesquisadores estarāo em todos os ambulatórios do setor de uveites do HCFMRP. USP recrutando sujeitos elegiveis. Além disso, tem-se a consciéncia que a frequencia de possiveis complicaçōes encontrada nẫo pode ser extrapolada para todas as pessoas com toxoplasmose ocular residentes dos municipios atendidos, pois possiveimente parte delas são assintomáticas e por isso não chegam a procurar atendimento oftalmológico. Esta informação será adicionada no momento da discussão dos achados. 4.8. Estimativa do tamanho da amostra Para o estudo em questão estimamos como 200 o número total de sujeitos, baseado na estimativa que mensalmente aproximadamente 15 pacientes com o diagnóstico de toxoplasmose ocular sāo atendidos no ambulatório do setor de Uveites no HCFMRP.USP.

\section{Consideraçōes sobre os Termos de apresentação obrigatória:}

Não há.

\section{Recomendaçōes:}

Não se aplica.

Enderepo: CAMPUS UNIVERSITÁAIO

Bairro: NONTE NLEGRE CEP: 14.049 .900

UF: SP Municipio: RIBEIRAO PRETO

Telefone: (16)3602-2228 Fax: (16)3633-1144 E-mail: cep@ncrp.usp.br 


\section{HOSPITAL DAS CLÍNICAS DA $\square$ FACULDADE DE MEDICINA DE USP - RIBEIRÃO RIBEIRÃO PRETO DA USP .}

Cortinusclo do Parecer: 1.153720

\section{Conclusōes ou Pendências e Lista de Inadequaçōes:}

Diante do exposto e à luz da Resoluçăo CNS 466/2012 e suas complementares, o projeto de pesquisa versẫo 2 de 06/07/2015, assim como o Termo de Consentimento Livre e Esclarecido versão 2 de 06/07/2015, podem ser enquadrados na categoria APROVADO.

\section{Situaçāo do Parecer:}

Aprovado

Necessita Apreciação da CONEP:

Não

Consideraçōes Finais a critério do CEP:

Projeto Aprovado: Tendo em vista a legislaçāo vigente, devem ser encaminhados ao CEP, relatórios parciais anuais referentes ao andamento da pesquisa e relatório final ao término do trabalho. Qualquer modificaçăo do projeto original deve ser apresentada a este CEP em nova versẫo, de forma objetiva e com justificativas, para nova apreciação.

RIBEIRAO PRETO, 20 de Julho de 2015

Assinado por:

MARCIA GUIMARĀES VILLANOVA

(Coordenador)

Enderepo: CAMPUS UNIVERSITÁRIO

Bairro: NONTE ALEGRE

UF: SP Município: RIBEIRAO PRETO

Telefone: (16)3602-2228 $\quad$ Fax: (16)3633-1144 E-mail: cepæhorp usp.tor 


\section{ANEXO B}

\section{TERMO DE CONSENTIMENTO LIVRE E ESCLARECIDO}

Prezado(a) senhor(a):

O(A) Senhor(a) está convidado a participar do Projeto: Manifestações clínicas e complicações associadas a toxoplasmose ocular, como sujeito de pesquisa. Esta pesquisa será realizada sob a responsabilidade do Prof. Dr. João Marcello Fortes Furtado, da Faculdade de Medicina de Ribeirão Preto da Universidade de São Paulo.

Queremos realizar o projeto para melhor entender manifestações oculares de uma doença que se chama Toxoplasmose. Esta infecção pode circular entre as pessoas sem que elas sintam qualquer sintoma ou sinal da doença. Mas parte delas pode desenvolver lesões oculares, com a presença ou não de sintomas.

Você pode concordar ou não em participar, ou desistir de participar em qualquer fase da pesquisa, sem que isso afete em nada o seu relacionamento com o Hospital das Clínicas da Faculdade de Medicina de Ribeirão Preto (HCFMRP), continuando você com os mesmos direitos de assistência médica sempre que precisar. Se tiver dúvidas durante a pesquisa, serão fornecidos esclarecimentos.

O senhor(a) está sendo convidado pois seu exame de sangue apresenta resultado positivo para a Toxoplasmose, além de apresentar alterações no fundo de olho compatíveis com Toxoplasmose ocular. Caso deseje participar, os detalhes do exame clínico e algumas informações sobre você serão incluídas em um banco de dados, para que possamos estudar melhor as complicações que esta doença pode causar no seu olho e em outras pessoas com quadro semelhante. Suas consultas continuarão a serem feitas no mesmo ambulatório do Hospital das Clínicas da Faculdade de Medicina de Ribeirão Preto.

Caso o senhor(a) concorde em participar, será convidado para ser submetido a um exame semelhante ao que já é feito em todas as suas avaliações rotineiras, consistindo de: medida da acuidade visual, exame da parte anterior do olho e também de fundo de olho. Para isso é necessário dilatar as suas pupilas, com um colírio. Você pode sentir dificuldade visual para perto por algumas horas, mas este desconforto é passageiro e não trará prejuízos para a sua saúde. Para minimizar esse desconforto evite iluminação excessiva e a realização de atividades para perto, por seis horas.

Sua inclusão no estudo não trará benefício extra para você, mas espera-se que ao final do estudo os pesquisadores envolvidos e a comunidade científica tenha um melhor entendimento das lesões que a Toxoplasmose pode causar em pessoas acometidas.

Em nenhum momento a sua identidade e os eventuais resultados dos exames serão divulgados de maneira a permitir a sua identificação.

O (A) senhor(a) não receberá pagamentos ou auxílios por participar desta pesquisa mas, caso haja qualquer dúvida ou desconforto relacionado a sua inclusão 
no estudo, você será atendido no HCFMRP, pelos pesquisadores e membros da equipe (cujos contatos estão abaixo relacionados). Se ocorrer dano decorrente da participação da pesquisa você terá direito à indenização conforme as leis vigentes no país.

Rubrica do Pesquisador

Rubrica do participante

Você receberá uma via do presente Termo de Consentimento Livre e Esclarecido, assinado e rubricado, em todas as paginas, pelo(a) senhor(a) e pelo pesquisador responsável. Caso tenha dúvidas éticas sobre a pesquisa e queira entrar em contato com o Comitê de Ética em Pesquisa utilize uma das seguintes formas de contato:

E-mail: cep@hcrp.usp.br. Endereço: Hospital das Clinicas. Bairro: CEP: 14048-900. Telefone: (16)3602-2228, CAMPUS UNIVERSITÁRIO MONTE ALEGRE. UF: SP Município: RIBEIRAO PRETO

\begin{tabular}{lll}
\hline Nome do Pesquisador & Assinatura do Pesquisador
\end{tabular}

Nome do Participante $\quad$ Assinatura do Participante Data

ou

Nome do Responsável Assinatura do Responsável Data

Pesquisador responsável:

Prof. Dr. João Marcello Fortes Furtado. Professor Doutor da Universidade de São Paulo, Faculdade de Medicina de Ribeirão Preto. Avenida Bandeirantes, 3900, CEP 14049-900

Se você tiver qualquer dúvida, sinta-se à vontade para nos contatar nos telefones: 16 3602-2523; 16 3602-2499 e email furtadojm@fmrp.usp.br 


\section{ANEXO C}

\section{FORMULÁRIO DE COLETA DE DADOS (ADMISSÃO)}

Iniciais do examinador:

Data: Código do Estudo:

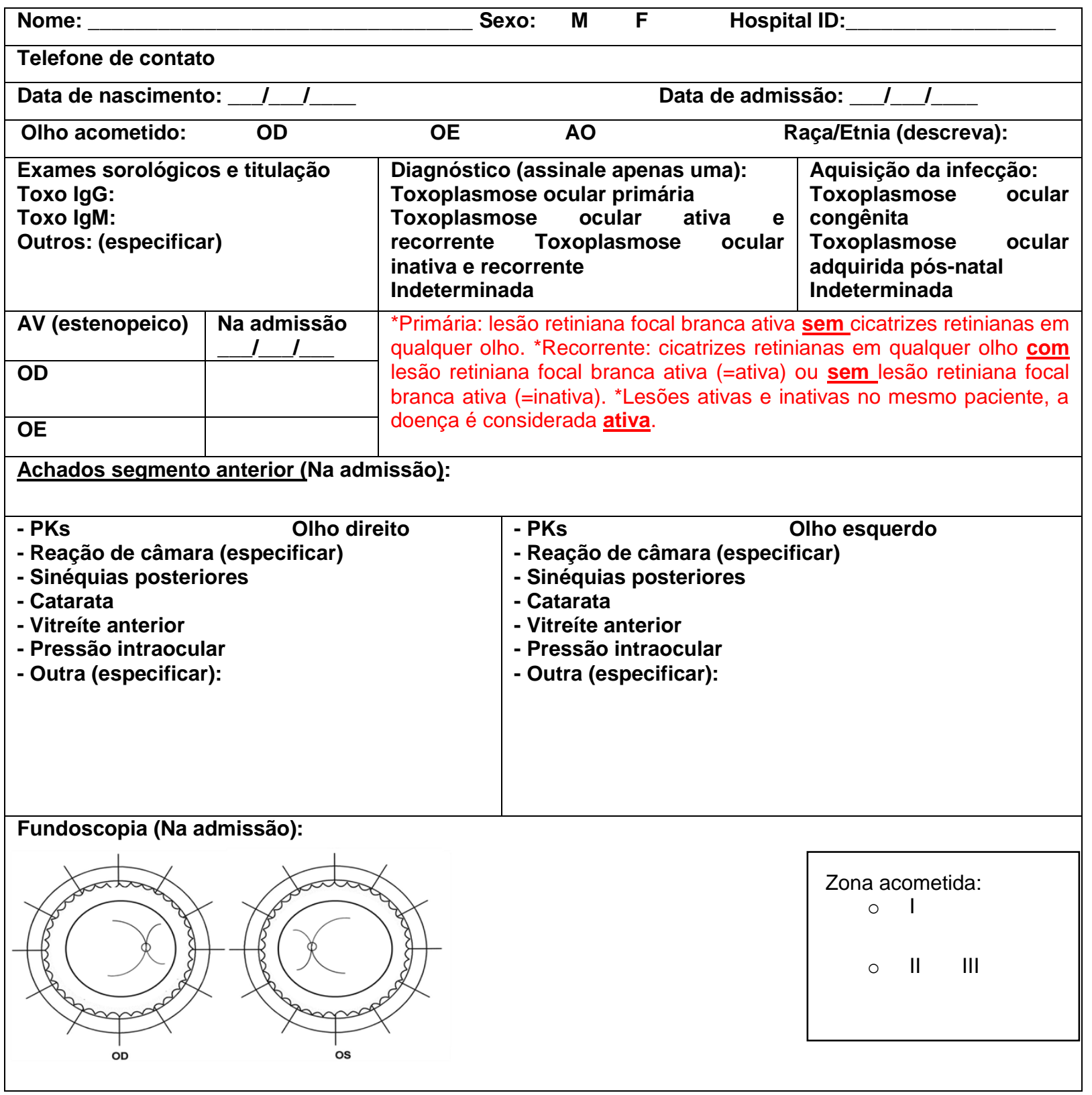




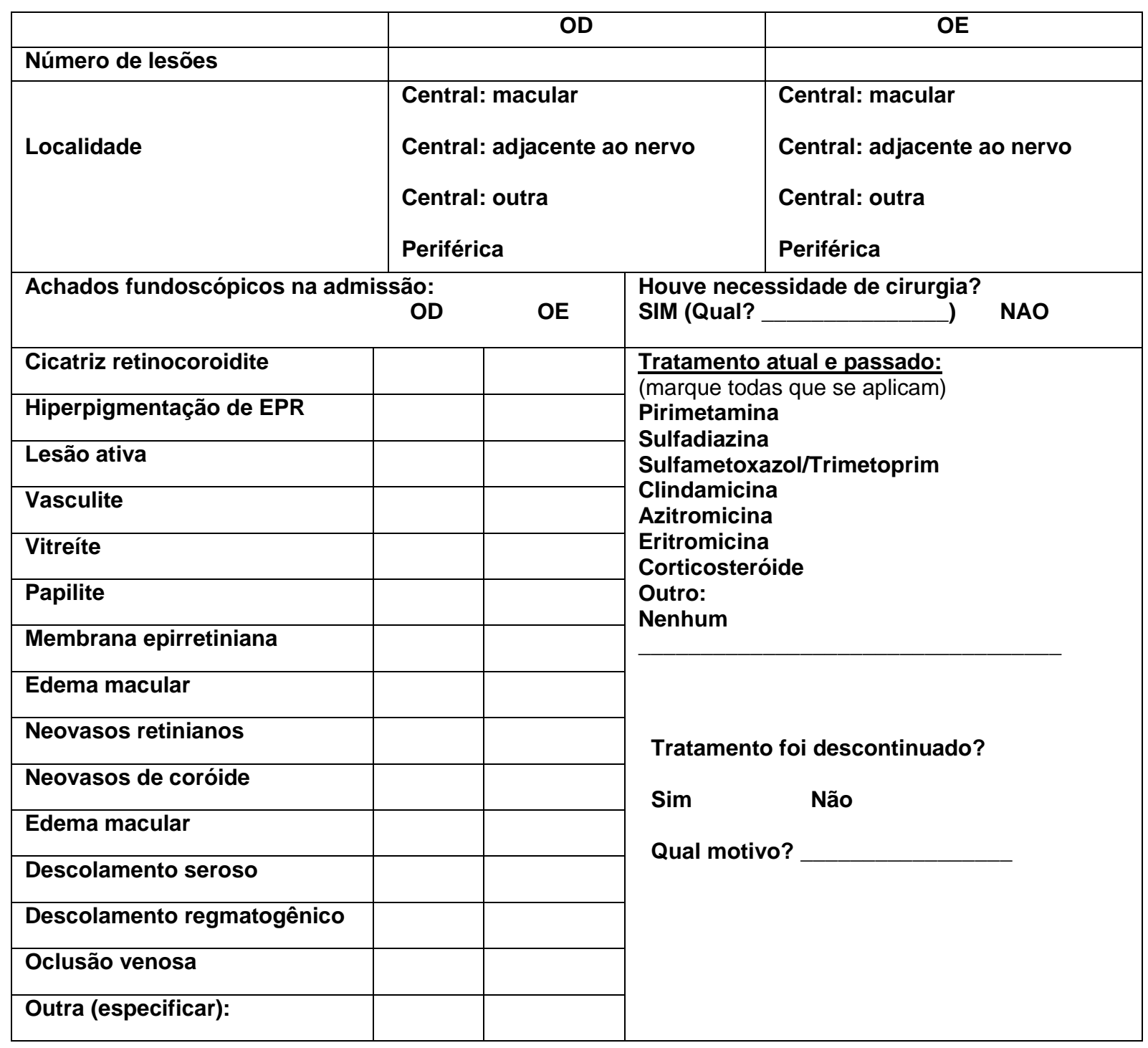




\section{ANEXO D}

\section{FORMULÁRIO DE COLETA DE DADOS (RETORNO)}

Nome do Examinador: Data (retorno):

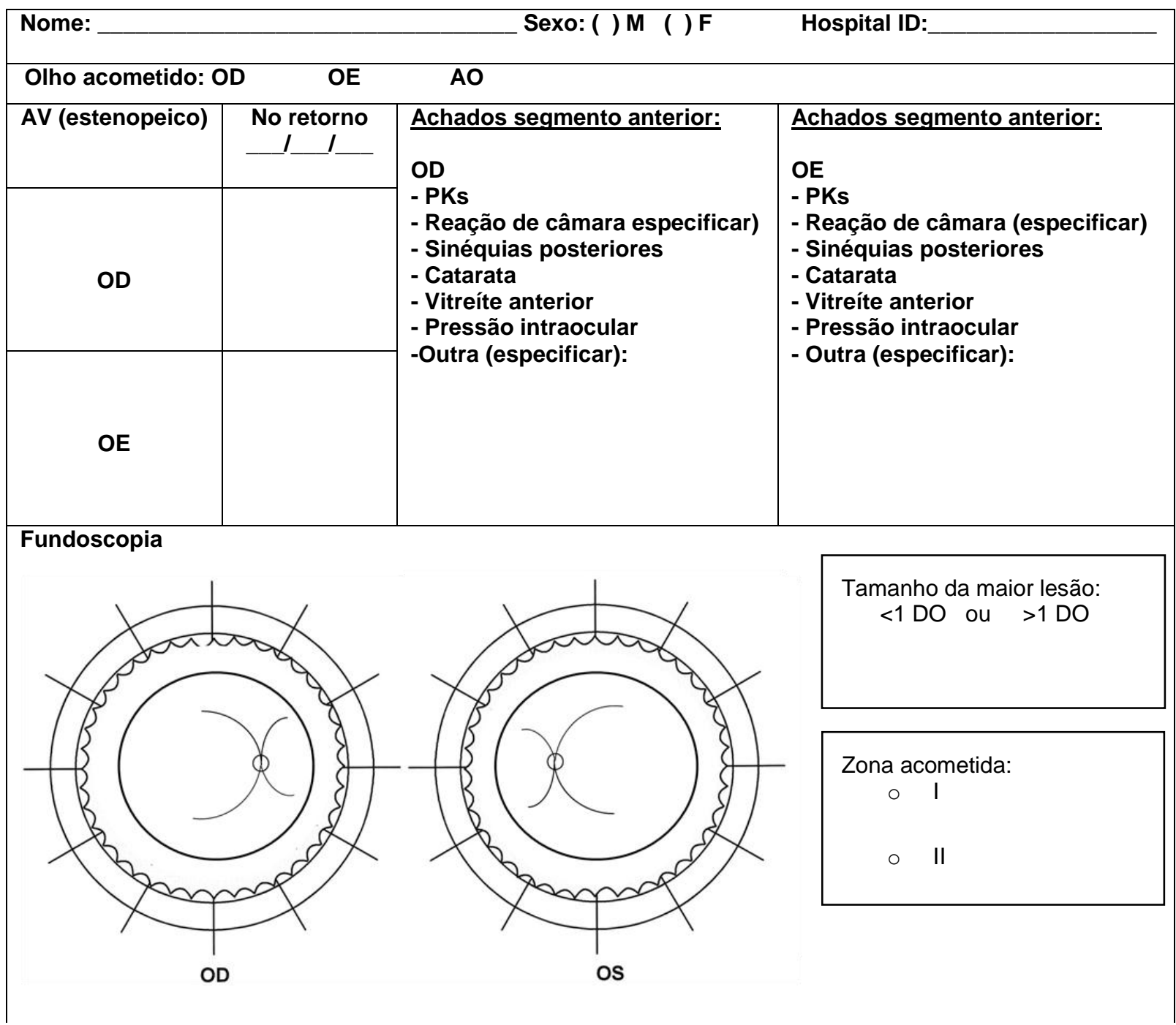




\begin{tabular}{|c|c|c|c|}
\hline & \multicolumn{2}{|c|}{ OD } & OE \\
\hline \multicolumn{4}{|l|}{ Número de lesões } \\
\hline Localidade & \multicolumn{2}{|c|}{$\begin{array}{l}\text { Central: macular } \\
\text { Central: adjacente ao nervo } \\
\text { Central: outra } \\
\text { Periférica }\end{array}$} & $\begin{array}{l}\text { Central: macular } \\
\text { Central: adjacente ao nervo } \\
\text { Central: outra } \\
\text { Periférica }\end{array}$ \\
\hline \multicolumn{2}{|c|}{ Achados fundoscópicos na admissão: } & \multicolumn{2}{|c|}{$\begin{array}{l}\text { Houve necessidade de cirurgia? } \\
\text { SIM (Qual? }\end{array}$} \\
\hline $\begin{array}{l}\text { Cicatriz retinocoroidite } \\
\text { Hiperpigmentação de EPR }\end{array}$ & & \multicolumn{2}{|c|}{ Medicação en } \\
\hline Lesão ativa & & \multicolumn{2}{|c|}{ Pirimetamina } \\
\hline Vasculite & & \multirow{2}{*}{\multicolumn{2}{|c|}{$\begin{array}{l}\text { Sulfadiazina } \\
\text { Sulfametoxazol/Trimetoprim }\end{array}$}} \\
\hline Vitreíte & & & \\
\hline Papilite & & \multicolumn{2}{|c|}{ Clindamicina } \\
\hline Membrana epirretiniana & & \multirow{2}{*}{\multicolumn{2}{|c|}{$\begin{array}{l}\text { Azitromicina } \\
\text { Eritromicina }\end{array}$}} \\
\hline Edema macular & & & \\
\hline Neovasos retinianos & & \multicolumn{2}{|c|}{$\begin{array}{l}\text { Corticosteróide } \\
\text { Outro }\end{array}$} \\
\hline Neovasos de coroide & & \multicolumn{2}{|c|}{$\begin{array}{l}\text { Outro } \\
\text { Nenhum }\end{array}$} \\
\hline Edema macular & & \multirow{2}{*}{\multicolumn{2}{|c|}{ Tratamento foi descontinuado? }} \\
\hline Descolamento seroso & & & \\
\hline Descolamento regmatogênico & & \multirow[t]{3}{*}{ Sim } & Não \\
\hline Oclusão venosa & & & \\
\hline Outra (especificar): & & & \\
\hline
\end{tabular}

CONDUTA:

PROXIMO RETORNO: 